\title{
A Chemical Screen Identifies Novel Compounds That Overcome Glial-Mediated Inhibition of Neuronal Regeneration
}

\author{
Lynn C. Usher, ${ }^{4 \star}$ Andrea Johnstone, ${ }^{4,5 \star}$ Ali Ertürk, ${ }^{6}$ Ying Hu, ${ }^{3}$ Dinara Strikis, ${ }^{4}$ Ina B. Wanner, ${ }^{4,5}$ Sanne Moorman, ${ }^{9}$ \\ Jae-Wook Lee, ${ }^{8}$ Jaeki Min, ${ }^{8}$ Hyung-Ho Ha, ${ }^{8}$ Yuanli Duan, ${ }^{3}$ Stanley Hoffman, ${ }^{7}$ Jeffrey L. Goldberg, ${ }^{3,5}$ Frank Bradke, ${ }^{6}$ \\ Young-Tae Chang, ${ }^{8}$ Vance P. Lemmon, ${ }^{2,4,5}$ and John L. Bixby ${ }^{1,2,4,5}$ \\ Departments of ${ }^{1}$ Pharmacology, ${ }^{2}$ Neurological Surgery, and ${ }^{3}$ Ophthalmology, and ${ }^{4}$ Miami Project to Cure Paralysis, ${ }^{5}$ Neuroscience Program, University of \\ Miami Miller School of Medicine, Miami, Florida 33136, ${ }^{6}$ Laboratory of Axon Growth and Regeneration, Max Planck Institute of Neurobiology, 82152 \\ Martinsried, Germany, ${ }^{7}$ Department of Rheumatology, Medical University of South Carolina, Charleston, South Carolina 29425, ${ }^{8}$ Department of Chemistry, \\ National University of Singapore, Singapore 117543, and ${ }^{9}$ Program in Neuroscience and Cognition, Utrecht University, $3584 \mathrm{CH}$ Utrecht, The Netherlands
}

A major barrier to regeneration of CNS axons is the presence of growth-inhibitory proteins associated with myelin and the glial scar. To identify chemical compounds with the ability to overcome the inhibition of regeneration, we screened a novel triazine library, based on the ability of compounds to increase neurite outgrowth from cerebellar neurons on inhibitory myelin substrates. The screen produced four "hit compounds," which act with nanomolar potency on several different neuronal types and on several distinct substrates relevant to glial inhibition. Moreover, the compounds selectively overcome inhibition rather than promote growth in general. The compounds do not affect neuronal cAMP levels, PKC activity, or EGFR (epidermal growth factor receptor) activation. Interestingly, one of the compounds alters microtubule dynamics and increases microtubule density in both fibroblasts and neurons. This same compound promotes regeneration of dorsal column axons after acute lesions and potentiates regeneration of optic nerve axons after nerve crush in vivo. These compounds should provide insight into the mechanisms through which glial-derived inhibitors of regeneration act, and could lead to the development of novel therapies for CNS injury.

\section{Introduction}

CNS injury results in irreversible deficits caused by poor axonal regeneration. Regeneration failure is partly attributable to axoninhibitory proteins derived from CNS myelin and the formation of a glial scar (Schwab et al., 2001; Bunge and Pearse, 2003; Silver and Miller, 2004). Thus, strategies to promote regeneration de-

\footnotetext{
Received Jan. 19, 2010; accepted Feb. 16, 2010.

This work was supported by grants from the Paralyzed Veterans of America (J.L.B., L.C.U.); The Craig Neilson Foundation (J.L.B., V.P.L.); National Institutes of Health (NIH)-National Institute of Neurological Disorders and Stroke Grants NS059866 (J.L.B.), NS061348 (J.L.G.), and NS063593 (A.J., J.L.B.); NIH-National Institute of Child Health and Human Development Grant HD057632 (V.P.L.); NIH-National Eye Institute Grant EY014801 (J.L.G.); The Wallace Coulter Foundation (J.L.B., V.P.L.); The Buoniconti Foundation (J.L.B., V.P.L.); The Walter G. Ross Foundation (V.P.L.); Deutsche Forschungsgemeinschaft (F.B.); the European Union Research Training Network (A.E., F.B.); and Research to Prevent Blindness (unrestricted). A.J. was a fellow of the University of Miami/Max-Planck-Institute Trainee Exchange Program. J.L.B., V.P.L., L.C.U., J.-W.L., and Y.-T.C. have applied for a patent based on the compounds described in this manuscript. We thank Dr. Jeremy Brockes for helpful discussions about compound libraries, Alejandra Weisman for help with RGC culture, and Amit Jain and Russell Early for analysis of the scar model experiments.

*L.C.U. and A.J. contributed equally to this work.

Correspondence should be addressed to John L. Bixby, LPLC 4-17, The Miami Project to Cure Paralysis, University of Miami Miller School of Medicine, 1095 Northwest 14th Terrace, Miami FL33136. E-mail: jbixby@med.miami.edu. L. C. Usher's present address: Universidad Icesi, Cali, Colombia.

I. B. Wanner's present address: Semel Institute for Neuroscience and Human Behavior, David Geffen School of Medicine, University of California, Los Angeles, Los Angeles, CA 90095.

J.-W. Lee's present address: Department of Chemistry, New York University, New York, NY 10003.

DOI:10.1523/JNEUROSCI.0302-10.2010

Copyright $\odot 2010$ the authors $\quad 0270-6474 / 10 / 304693-14 \$ 15.00 / 0$
}

pend on understanding the signaling processes triggered in neurons by these glial-derived inhibitory proteins.

Inhibitory properties of CNS myelin are associated with the presence of Nogo, oligodendrocyte-myelin glycoprotein, and myelin-associated glycoprotein (Domeniconi and Filbin, 2005). However, myelin and oligodendrocytes contain other inhibitory cues (Miranda et al., 1999; Pesheva and Probstmeier, 2000; Moreau-Fauvarque et al., 2003; Goldberg et al., 2004; Benson et al., 2005; Fabes et al., 2006). Similarly, cells of the glial scar produce a variety of axon growth-inhibitory proteins (McKeon et al., 1991; Fitch and Silver, 1997; De Winter et al., 2002; Bundesen et al., 2003; Hagino et al., 2003; Tang et al., 2003; Schwab et al., 2005; Matsuura et al., 2008; Miyashita et al., 2009). Among these, chondroitin sulfate proteoglycans (CSPGs) seem particularly important (Moon et al., 2001; Bradbury et al., 2002).

Strategies to improve CNS regeneration often target myelin inhibitors or their receptors (Schnell et al., 1994; GrandPré et al., 2002; Li et al., 2004), or attempt to decrease expression of inhibitory CSPGs (Bradbury et al., 2002; Moon et al., 2003; Davies et al., 2004; Grimpe and Silver, 2004; Houle et al., 2006; Laabs et al., 2007) or receptors (Shen et al., 2009). A second approach is to target the signal transduction cascades triggered by inhibitory proteins. For example, increases in cAMP, or inhibition of Rho or Rho kinase (ROCK), have each been shown to improve growth from neurons challenged with inhibitory substrates in vitro and to increase regeneration in vivo (Lehmann et al., 1999; Dergham 
et al., 2002; McKerracher and Higuchi, 2006; Lingor et al., 2007). However, our understanding of regeneration inhibitors, their neuronal receptors, and their signal transduction pathways is clearly incomplete. This difficulty can be circumvented by a strategy that functions without complete knowledge of underlying mechanisms. Regeneration-inhibiting signals should eventually converge on common regulatory signals, at signaling "nodes." If so, using a screening approach, one might identify chemical compounds that target such nodes. Indeed, a phenotypic screen testing a small library of known bioactive compounds for the ability to overcome inhibition of neurite growth has identified conventional PKC (cPKC) and the epidermal growth factor receptor (EGFR) as potential targets for improving regeneration (Sivasankaran et al., 2004; Koprivica et al., 2005).

Screens using known bioactives are limited, because only a small fraction of the proteome is targeted by known compounds. We therefore conducted a screen using a novel library of compounds with unknown biological targets. The screen identified four novel compounds that overcome inhibition of neurite outgrowth by CNS myelin. These compounds overcame inhibition of neurite growth from a variety of neuronal types challenged with a variety of substrates. Most significantly, one of them improved regeneration of dorsal column and optic nerve axons after injury in vivo.

\section{Materials and Methods}

Materials. The CSPG mixture was prepared as described previously (Ernst et al., 1995). The anti- $\beta$-tubulin antibody E7 was produced from the hybridoma (Developmental Studies Hybridoma Bank, University of Iowa, Iowa City, IA). We also used guinea pig anti-GFAP (Advanced Immunochemical), rabbit anti- $\beta 3$ tubulin (Covance), mouse antifibronectin (BD Biosciences Transduction Laboratories), rat antityrosinated tubulin (Abcam), mouse anti-acetylated tubulin (Abcam), rabbit anti-Rho (26C4; Santa Cruz), rabbit anti-pPKC ( $\beta$ II Ser660; Cell Signaling), goat anti-PKC ( $\beta$ II C18; Cell Signaling), rabbit anti-pEGFR (Y1173; Cell Signaling), rabbit anti-EGFR (Cell Signaling), mouse antiGAPDH (Santa Cruz), and chick anti-GAP43 (Novus). Fluorescent secondary antibodies (Alexa Fluor labeled) were from Invitrogen and Rockland Immunochemicals. Phorbol myristate acetate was from Calbiochem, and protease inhibitors were from Roche. Elvax was from DuPont. Other chemicals were from Sigma-Aldrich and Millipore, and tissue culture reagents were from Invitrogen. The cAMP enzyme immunoassay kit (AK-205) was purchased from BIOMOL. The PepTag assay for protein kinase C (V3550) was from Promega.

The triazine library was synthesized by a "building-block" approach (Lee et al., 2009). Each compound is a trisubstituted triazine, with one substituent group being a triethylene glycol linker, and the other two substituents varying. Stock solutions were dissolved at $10 \mathrm{~mm}$ in dimethylsulfoxide (DMSO) and were further diluted to $100 \mu \mathrm{M}$ in culture medium before dilution in wells at appropriate concentrations. The compound F05 from several different lots synthesized at different times was used in these experiments with comparable results.

Substrate preparation. CNS myelin was purified from mouse brain using a modification of previously described protocols (Norton and Poduslo, 1973; Colman et al., 1982). Briefly, brains from 12 postnatal day 25 (P25) mice were homogenized in $25 \mathrm{ml}$ of cold $0.32 \mathrm{M}$ sucrose, and 3.2 $\mathrm{M}$ sucrose containing protease inhibitor mixture (Roche) was added to a final concentration of $1.2 \mathrm{M}$ before rehomogenization. Each homogenate was overlaid with $0.85 \mathrm{M}$ sucrose followed by $0.32 \mathrm{M}$ sucrose (all contained protease inhibitors) before centrifugation ( $2 \mathrm{~h} ; 21,000 \mathrm{rpm}$; SW28 rotor). Myelin was collected from the $0.32 \mathrm{M} / 0.85 \mathrm{M}$ interface, triturated in $10 \mathrm{~mm}$ HEPES, pH 7.4, and pelleted (27,500 rpm; $15 \mathrm{~min}$ ). Pellets were washed two times, and then resuspended $(1 \mathrm{mg} / \mathrm{ml})$ in $20 \mathrm{~mm} \mathrm{HEPES}$ and stored at $-80^{\circ} \mathrm{C}$. Each well of a poly-D-lysine (PDL)-coated 96-well plate was coated with $25 \mathrm{ng}$ of myelin in $60 \mu \mathrm{l}$ of $10 \mathrm{~mm}$ HEPES warmed to $37^{\circ} \mathrm{C}$. The myelin was dried onto the plate under vacuum for $2-3 \mathrm{~h}$ before exposure to UV light for $30 \mathrm{~min}$.
One hundred microliters of a premixed solution containing $500 \mathrm{ng} / \mathrm{ml}$ CSPG and $5 \mu \mathrm{g} / \mathrm{ml}$ laminin 1 (Sigma-Aldrich) in PBS were incubated on each well of a PDL-coated 96-well plate overnight $(\mathrm{O} / \mathrm{N})$ at $4^{\circ} \mathrm{C}$. Wells were washed two times with PBS before plating cells. In 24-well plates, each well was each coated with $500 \mu \mathrm{l}$ of a $3 \mu \mathrm{g} / \mathrm{ml} \mathrm{CSPG} / 5 \mu \mathrm{g} / \mathrm{ml}$ laminin (LN) mixture.

Cell culture. P8 mouse cerebella from C57BL/6 mice were dissected and dissociated as previously described (Cheng et al., 2005). Cells were immediately plated at a density of 3000 cells/well in 96 -well plates. Compounds were added $1 \mathrm{~h}$ after plating. Cells were grown for $48 \mathrm{~h}$ in DMEM, supplemented with $10 \%$ fetal bovine serum (FBS), Glutamax (2 mM), sodium pyruvate (1 mM), HEPES (25 mM), pH 7.4, $\mathrm{KCl}(25 \mathrm{~mm})$, and antibiotics.

Spinal neurons were dissociated from embryonic day 14 (E14) rat spinal cord. After removal of the meninges, cords were incubated in $\mathrm{Ca}^{2+}$-free Hibernate medium (BrainBits) containing 0.25\% trypsin (no. 15090; Invitrogen) and $600 \mu \mathrm{g} / \mathrm{ml} \mathrm{DNase}$ for $15 \mathrm{~min}$ at $37^{\circ} \mathrm{C}$. The tissue was then rinsed five times for $2 \mathrm{~min}$ each with $\mathrm{Ca}^{2+}$-free Hibernate medium supplemented with B-27 (Invitrogen), followed by trituration with a fire-polished Pasteur pipette before plating at $2 \times 10^{5}$ cells per 24 -well plate well. E18 cortical neurons were purchased from Lonza. They were rapidly thawed and resuspended in Neurobasal medium with $5 \%$ FBS before plating at $4 \times 10^{5}$ cell per 24 -well plate well. Retinal ganglion cells (RGCs) from P20 Sprague Dawley rats were purified by sequential immunopanning as described previously (Barres et al., 1988; Meyer-Franke et al., 1995) and plated at $10^{4}$ cells per 24-well plate well in serum-free defined medium (Wang et al., 2007) containing BDNF (50 $\mathrm{ng} / \mathrm{ml}), \mathrm{CNTF}(10 \mathrm{ng} / \mathrm{ml})$, insulin $(5 \mu \mathrm{g} / \mathrm{ml})$, and forskolin $(5 \mu \mathrm{M})$. Compounds (or DMSO controls) were added $10 \mathrm{~min}$ after plating (or $1 \mathrm{~h}$ after plating for RGCs). Hippocampal neurons were dissected from E18 rats and dissociated as described previously (Bradke and Dotti, 1997). They were plated on coverslips coated with PDL or with $5 \mu \mathrm{g} / \mathrm{ml} \mathrm{laminin} \mathrm{plus}$ $1 \mu \mathrm{g} / \mathrm{ml}$ CSPGs and treated with F05 (or vehicle) for either 1 or $48 \mathrm{~h}$. Cells were fixed with $4 \%$ paraformaldehyde $/ 4 \%$ sucrose in PBS solution before staining. COS cells were plated on PDL-coated coverslips, treated for $1 \mathrm{~h}$ with F05 (or vehicle), and fixed with $4 \%$ paraformaldehyde/ $0.1 \%$ glutaraldehyde in an isosmotic HEPES-buffered solution. In microtubule (MT) staining experiments, cells were simultaneously fixed and permeabilized using a PHEM buffer (60 mM PIPES, 25 mM HEPES, $5 \mathrm{~mm}$ EGTA, and $1 \mathrm{~mm} \mathrm{MgCl}$ ) with $0.25 \%$ glutaraldehyde, $3.7 \%$ paraformaldehyde, $3.7 \%$ sucrose, and $0.1 \%$ Triton X-100, essentially as described previously (Witte et al., 2008). Fluorescence images of randomly chosen growth cones for each condition were taken using a microscope (Olympus) with a $60 \times$ oil objective. Equal exposures were used for each respective channel, taking care to avoid overexposure. Quantitative measurements of growth cone area and of tyrosinated and acetylated microtubules were determined using MetaMorph software. A $20 \mu \mathrm{m}$ segment of the growth cone and distal axon shaft were traced in the GAP-43 channel. The area and average fluorescence intensity of the tyrosinated and acetylated tubulin in the trace were recorded. The average fluorescence intensity was multiplied by the area to determine the integrated total intensity. This was then subtracted from a background measurement.

Glial scar model. An in vitro model of the glial scar (scar model) was produced by subjecting cultures of differentiated astrocytes, or cocultures of differentiated astrocytes and meningeal fibroblasts, to mechanical stretch injury as described previously (Wanner et al., 2008). To allow expression of growth inhibitors, fibroblast addition was done $72 \mathrm{~h}$ before addition of neurons, and stretching was done $24 \mathrm{~h}$ before addition of neurons. E17 dorsal root ganglion neurons were precultured with fluorodeoxyuridine for 2 weeks to remove glial cells, and then dissociated with collagenase and trypsin before plating $\left(3 \times 10^{4}\right.$ cells/well $)$ onto the scar model (Wanner et al., 2008). Cortical neurons were dissociated from P6 sensorimotor cortex and plated onto the scar model as described previously (Wanner et al., 2008). F05 ( $1 \mu \mathrm{M}$; or DMSO as a control) was added at the time of plating of the neurons. Both neuronal types were cultured for $24 \mathrm{~h}$. Observations of multiple microscope fields in control and treated cultures did not reveal any effects of F05 on the morphology of the astrocyte cultures (data not shown). Staining for neurons, GFAP, tenas- 
cin, and CSPGs (CS56 antibody) was performed as described previously (Wanner et al., 2008).

Immunocytochemistry. Immunocytochemistry in 96-well plates was performed using a QIAGEN Biorobot3000 and/or a Hydra II from Matrix Technologies. Cells were fixed with $4 \%$ paraformaldehyde containing $0.01 \%$ glutaraldehyde for $20 \mathrm{~min}$ followed by permeabilization and blocking for $20 \mathrm{~min}$ at room temperature with a solution containing $0.05 \%$ saponin, $5 \%$ goat serum, and $0.02 \%$ sodium azide. Cells were then incubated for $1 \mathrm{~h}$ at room temperature (RT) with a primary antibody to $\beta$-tubulin (E7; 1:1000) and then with a secondary antibody (goat antimouse Alexa Fluor 488; $1: 500$ ) for $1 \mathrm{~h}$ at RT. Neuronal cultures in 24-well plates were fixed and stained by hand using the same procedures. Cells on coverslips were incubated in primary antibody overnight at $4^{\circ} \mathrm{C}$, washed two times, incubated with secondary antibodies for $1 \mathrm{~h}$ at RT, washed two times, and then mounted using Gelmount (Biomeda). Hippocampal neurons were treated with $50 \mathrm{~mm} \mathrm{NH}_{4} \mathrm{Cl}$ and blocked with $2 \% \mathrm{FBS}, 2 \%$ BSA, $0.2 \%$ fish gelatin in PBS before staining. Glial scar cultures were fixed and stained as described previously (Wanner et al., 2008).

Image acquisition and analysis. Experiments in 96-well format were imaged using the KineticScan Reader (KSR) (Cellomics) and analyzed using the Cellomics Extended Neurite Outgrowth and/or Neuronal Profiling bioapplication software. Only cells with a valid nucleus and cell body (as determined by bioapplication software) were included in the analysis. Mean total neurite length per neuron and mean average neurite length per neuron were determined for 200-300 neurons per condition. For experiments in 24-well format, images were taken using an OPX 285C microscope camera (ImagingPlanet) and a Nikon inverted microscope. Fields for culture analysis were selected randomly, except for experiments in 96-well plates in which the same fields were automatically sampled in each well. Statistics were repeated-measures ANOVA, ANOVA with post test (for multiple comparisons), or unpaired $t$ tests (Instat; GraphPad). Images were analyzed using Neurolucida and Neuroexplorer (MicroBrightField). Neurolucida was used to trace neurites and analysis of total neurite length was done using Neuroexplorer. Total neurite length is the sum of the lengths of all neuritic processes associated with a single neuron. Confocal imaging was done at $100 \times$ magnification on a Zeiss LSM 510 microscope.

cAMP assay. P8 mouse cerebellar granule neurons were plated at a density of 300,000 cells/well in a 12-well dish on PDL alone or on PDL/ myelin $(1 \mu \mathrm{g} / \mathrm{ml})$. Each of the four compounds (A05, C05, F05, and H08) was added at a final concentration of $5 \mu \mathrm{M}$ at the time of plating. Cells were grown on myelin or on PDL in the absence of the compounds as controls. The cells were grown in culture for $48 \mathrm{~h}$ at $37^{\circ} \mathrm{C}$. Thirty minutes before performance of the cAMP assay, varying concentrations of forskolin $(10,50,100$, and $250 \mu \mathrm{M})$ were added to the cells. The cAMP assay was performed according to the manufacturer's instructions (catalog \#AK-205; BIOMOL International). Optical density (405 nm) was read on a microplate reader. The experiment was repeated on cells that had been grown in culture for $2 \mathrm{~h}$, with similar results to those seen for $48 \mathrm{~h}$ cultures.

Measurement of protein kinase $C$ activity. For in vitro $\mathrm{PKC}$ activity (using PepTag), each of the four compounds (A05, C05, F05 and H08) was tested at $100 \mathrm{~nm}$ and $1 \mu \mathrm{M}$ concentrations. Calphostin $\mathrm{C}$ at concentrations of $500 \mathrm{~nm}$ and $1 \mu \mathrm{m}$ was used as a positive control. The assay was performed according to manufacturer's instructions (Promega) with the following adjustments. PKC was added to the test compounds in Eppendorf tubes followed by PepTag peptide and PKC activator solution. This solution was incubated at RT for $20 \mathrm{~min}$. The tubes were then incubated for $2 \mathrm{~min}$ at $30^{\circ} \mathrm{C}$, and then PKC reaction buffer was added. After $30 \mathrm{~min}$ at $30^{\circ} \mathrm{C}$, the reactions were stopped according to the protocol. The samples were separated on $0.8 \%$ agarose gels in $50 \mathrm{~mm}$ Tris-Cl, $\mathrm{pH}$ 8.0. Bands were quantified using GeneSnap (Syngene) and GeneTools (Syngene) software. For measurements of PKC activation in neurons, CGNs were grown overnight in serum-containing media, then serum-starved for $4 \mathrm{~h}$ before treatment with PMA for $1 \mathrm{~h}$, in the absence or presence of $1 \mu \mathrm{M}$ F05. After treatment, the cells were rapidly lysed on ice in a buffer containing urea $(8 \mathrm{~m})$ supplemented with HEPES (20 mM), EDTA (5 mM), EGTA (5 mM), and sodium orthovanadate ( $0.1 \mathrm{~mm})$, Complete EDTAfree protease inhibitor (Roche), and a phosphatase inhibitor mixture
(Calbiochem Cocktail III). Cell lysates were run on two separate gels loaded identically and probed for total PKC and for phospho-PKC. In some cases, the same gels were probed simultaneously for pPKC and total PKC; results were comparable in these cases.

Epidermal growth factor receptor activation. The A431 cell assay was performed in accordance with the manufacturer's protocol (LI-COR Biosciences). Briefly, cells were grown to confluency in 96-well plates, serum starved $\mathrm{O} / \mathrm{N}$, and then treated with 4 -[3(bromophenyl)-amino]6-acrylamidoquinazoline (PD168393) $(1 \mu \mathrm{M})$, or A05, C05, F05, or H08 at indicated concentrations for $2 \mathrm{~h}$ before treatment with serum-free media with or without epidermal growth factor (EGF) $(100 \mathrm{ng} / \mathrm{ml})$ for $7.5 \mathrm{~min}$. Cells were then fixed with $4 \%$ paraformaldehye $/ 0.01 \%$ glutaraldehyde, permeabilized with $0.1 \%$ Triton X-100, and blocked with Odyssey blocking buffer (LI-COR). Cells were then incubated O/N at RT with primary antibodies (phospho-EGFR Tyr1045 and anti-EGFR). After five washes, cells were incubated with secondary antibodies for $1 \mathrm{~h}$ at RT. After washing, the plate was scanned using the Odyssey Infrared Imaging System, and data were analyzed using Odyssey In-Cell Western software. EGFR activity levels were expressed as ratios of signal intensities for phospho-EGFR/total EGFR. For measurements of EGFR in neurons, cerebellar granule neurons (CGNs) were grown overnight in serum-free medium, and then treated with $1 \mu \mathrm{M}$ F05 or vehicle for $1 \mathrm{~h}$. During the last 10 min of incubation, EGFRs were activated with the indicated concentrations of EGF (or vehicle). Cells were lysed in a modified RIPA buffer containing activated sodium orthovanadate $(200 \mu \mathrm{M})$, Complete EDTA-free Protease Inhibitor (Roche), and a phosphatase inhibitor mixture (Calbiochem Cocktail III). Cleared lysates were run on two identical gels, blotted to nitrocellulose, and probed for pEGFR, total EGFR, and $\beta$-tubulin. Data for pEGFR were normalized either to total EGFR or to tubulin.

In vivo imaging. In vivo imaging of acutely injured axons was performed as described previously (Ertürk et al., 2007). Animals were anesthetized, and the lamina at the level of T13/L1 in 12-week-old female mice was removed to expose the dorsal columns in GFP-M mice (Feng et al., 2000). Iridectomy scissors were used to transect the dorsal columns bilaterally. F05 (10 $\mu \mathrm{M}, 100 \mu \mathrm{M}$, or vehicle control; $10 \mu \mathrm{l})$ was pipetted directly onto the lesion site immediately after injury. Compound or vehicle was reapplied every hour for the first $6 \mathrm{~h}$ (the skin and dura were reopened for compound application). Lesions were imaged every hour for the first $6 \mathrm{~h}$, using an Olympus SZX-12 fluorescent stereomicroscope equipped with $1 \times$ Plan Apochromat objective and 1.6× Plan Fluorite objective (Olympus). A ColorView II camera integrated to the microscope was used to capture images through Analysis FIVE software (Soft Imaging System). Six hours after the lesion, the injury site was covered with Gelfoam soaked with F05 or vehicle, the dura was closed, the skin was stapled, and the animals were returned to the cage. Animals were kept on $37^{\circ} \mathrm{C}$ heating pads during the operation and the imaging session. At $24 \mathrm{~h}$ and at $48 \mathrm{~h}$, animals were reanesthetized, the wounds were opened, and the axons were imaged again (fresh F05- or vehicle-soaked Gelfoam was applied at $24 \mathrm{~h}$ ). Animals were deeply anesthetized and perfused with paraformaldehyde $48 \mathrm{~h}$ after injury. Confocal images were acquired with a Leica SP2 confocal microscope system in sequential scanning mode. Every axon that was in focus in at least one image at each time point was analyzed. To quantify the "crossing distance" of "best axons" at each lesion, we measured the distances of the axonal tips to the proximal edge of the lesion using Analysis FIVE software. For axons behind the lesion, this was a negative number. If an axon reached or crossed the proximal edge of the lesion, the distance was given a positive number. The best axon was defined as the axon with the highest value in this assay (closest to the lesion if behind the lesion; farthest from the lesion if in front of the lesion). Retraction bulbs were evaluated as described by Ertürk et al. (2007). Percentage retraction bulbs was quantified as the total number of retraction bulbs divided by the total number of severed axons. Statistical analysis was performed using Instat (Kruskal-Wallis ANOVA test with post test).

Slow-release Elvax polymer for optic nerve experiments. Elvax was embedded with F05 (1 mM) or vehicle (10\% DMSO) using methods similar to those described previously (Rhine et al., 1980). Briefly, ethylene-vinyl acetate copolymer (Elvax 40W; DuPont) was washed in 95\% ethanol 
$(10 \% \mathrm{w} / \mathrm{v})$ for 1 week at $37^{\circ} \mathrm{C}$ with continuous stirring and daily changes. The Elvax was dried overnight at $37^{\circ} \mathrm{C}$ and then dissolved in dichloromethane (DCM) (Sigma-Aldrich) to yield a 10\% (w/v) solution. F05 (10 mM stock in $100 \%$ DMSO) or vehicle (100\% DMSO) was added to 2 $\mathrm{ml}$ of the dissolved Elvax in a glass test tube to achieve the desired final concentration. The mixture was vortexed vigorously and quickly poured onto a precooled glass mold. The mixture was allowed to freeze on dry ice for $10 \mathrm{~min}$. The solidified mixture was placed on a cheesecloth-covered platform at $-20^{\circ} \mathrm{C}$ for $2 \mathrm{~d}$ to allow the DCM to evaporate. The slab was then placed in a room temperature dessicator under a mild vacuum. The final Elvax slab was stored in the dark in a tightly closed container at $-20^{\circ} \mathrm{C}$. Release kinetics of $\mathrm{F} 05$ was tested by incubation of a small rectangle (the size/shape of those used in experiments) in saline followed by HPLC analysis together with an F05 standard curve. Detectable amounts of F05 were released over a period of at least $7 \mathrm{~d}$, with a large bolus released during the first day (data not shown).

Optic nerve crush. Optic nerve crush, tissue processing, imaging, and analysis were performed masked, such that the experimenters did not know the treatment group of the animal at any stage until the analysis was complete. In separate experiments looking at shorter-term postcrush survivals, we saw no spared axons $>0.2 \mathrm{~mm}$ beyond the crush site (data not shown). Adult (8-week-old) Sprague Dawley rats were anesthetized, and an incision was made just behind the eye. The optic nerve was exposed and the sheath opened longitudinally. The nerve was crushed 1 $\mathrm{mm}$ behind the eye with no. 5 forceps for $10 \mathrm{~s}$, avoiding injury to the ophthalmic artery. Nerve injury was verified visually at the crush site, whereas the vascular integrity of the retina was evaluated by fundoscopic examination. F05- or vehicle-embedded Elvax $(\sim 0.012$ g rectangular piece) was placed proximal to the crush site of the nerve. After suturing the wound, CNTF $(1 \mu \mathrm{g} / \mu \mathrm{l}$ in $1.5 \mu \mathrm{l}$ of PBS) and either F05 (100 $\mu \mathrm{m}$ in $3.5 \mu \mathrm{l}$ of PBS) or vehicle (1\% DMSO in $3.5 \mu \mathrm{l}$ of PBS) were injected intravitreally using a micropipette. Drug or vehicle was injected again at days 3, 7, and 10. Thirteen days after the initial injury, Alexa Fluor 488labeled cholera toxin B (CTB-488; $10 \mu \mathrm{g} / \mathrm{ml}$; Invitrogen) was injected intravitreally. Care was taken not to damage the lens. One day later, $14 \mathrm{~d}$ after injury, animals were deeply anesthetized and perfused with $4 \%$ PFA in $0.1 \mathrm{M}$ phosphate buffer. Optic nerves were dissected and postfixed in $4 \%$ PFA for $1 \mathrm{~h}$ and subsequently washed in PBS. Optic nerves were incubated in $30 \%$ sucrose at $4^{\circ} \mathrm{C}$ overnight before mounting in OCT and longitudinal sectioning at $40 \mu \mathrm{m}$ using a cryostat. The nerves were imaged with a $10 \times$ objective using a Zeiss LSM510 confocal microscope. To quantify regenerating axons, the crush site was identified, and we determined the number of axons that crossed $100 \mu \mathrm{m}$ increment distances from the crush as well as the length of the longest regenerating axon.

\section{Results}

\section{A novel library of substituted triazines}

Previous reports have described the rationale for development of combinatorial libraries based on the triazine backbone (Moon et al., 2002; Kim and Chang, 2007; Min et al., 2007). The library we have used, synthesized by a building-block approach (Lee et al., 2009), comprises trisubstituted triazines, with one substituent being a triethylene glycol linker, and the other two substituents varying. This library was chosen partially for the chemical properties of its constituents, which generally follow Lipinski's rules for the drug-like nature of small molecules (Lipinski et al., 2001). Compounds that adhere to these "rules," which include constraints on molecular size, hydrogen bond donors/acceptors, and lipophilicity, are more likely to be useful as "lead" compounds for drug discovery. Additionally, substituted triazines like those in our library have been found to be active on several aspects of cell growth and migration (Moon et al., 2002; Williams et al., 2004; Duckmanton et al., 2005; Kim et al., 2006; Min et al., 2007). The current library had not previously been tested in a cellular system.

\section{A phenotypic screen for overcoming myelin inhibition identifies four "hits"}

One barrier to regeneration of CNS axons consists of myelinassociated inhibitors in the injured tissue (Yiu and He, 2003). In a successful attempt to identify signals relevant to myelin inhibition, a previous study used CGNs grown on substrates of CNS myelin to screen a small library of known bioactive compounds (Sivasankaran et al., 2004; Koprivica et al., 2005). To identify novel reagents with the potential to overcome the inhibitory effects of CNS myelin, we screened compounds from our triazine library for the ability to increase neurite growth from P8 CGNs on CNS myelin substrates.

In our phenotypic screen, neurite outgrowth was evaluated after $48 \mathrm{~h}$ in vitro using the Cellomics KSR and the Cellomics Extended Neurite Outgrowth bioapplication (Fig. 1A,B). The KSR is an automated image analysis system for cells grown in multiwell plates. Initial experiments (data not shown) compared data collected in an automated manner (by KSR) with data acquired manually using Neurolucida analysis and demonstrated that the KSR readily identifies strong inhibition by myelin, as well as its reversal by dibutyryl cAMP (dbcAMP) (Domeniconi and Filbin, 2005). In addition to test wells with added compounds, each plate in the screen included wells with a PDL substrate, myelin wells with no added compound (negative control), and myelin wells with addition of $100 \mu \mathrm{M}$ dbcAMP as a positive control. The criterion for hits in this screen was an ability to increase neurite growth (mean total neurite length per neuron) to a level at least two times that observed on myelin alone. Many of the compounds screened had no substantial effect on neurite outgrowth on myelin (Fig. $1 F)$. In other cases, compounds led to reduced neurite growth on myelin. Although these compounds may reflect interaction with a specific pathway mediating inhibition of neurite growth, we chose not to investigate them further. Finally, four of the compounds were hits, leading to an increase in neurite growth comparable with that seen with dbcAMP (Fig. $1 D-F$ ). These four compounds (A05, C05, F05, and H08) comprise three structurally related compounds and one less closely related compound (Fig. $1 H$ ).

The four hit compounds have each been tested repeatedly in the myelin assay. The strong increases in neurite growth were reproducible (data not shown). As one measure of the selectivity of the activities of the compounds, we assessed dose-response relationships for each compound. In these experiments, the estimated $\mathrm{EC}_{50}$ values of the compounds ranged from $9 \mathrm{~nm}$ (F05) to $25 \mathrm{~nm}$ (A05) (Fig. 1G). Thus, the compounds are potent stimulators of neurite growth on myelin substrates, acting at nanomolar concentrations. The compounds were still able to increase growth at high concentrations $(10 \mu \mathrm{M})$ (data not shown); thus, they have a relatively high efficacy/toxicity ratio, at least in vitro.

\section{Hit compounds increase neurite growth on an inhibitory mixture of CSPGs}

Our hypothesis is that compounds can be identified that act at signaling nodes common to multiple types of inhibitory stimulus; such compounds should be active on more than one inhibitory substrate. Significant inhibition of regeneration after CNS injury stems from the glial scar (Reier and Houle, 1988; Davies et al., 1999; Fawcett and Asher, 1999; Silver and Miller, 2004), and a major group of inhibitory proteins in the glial scar comprises the CSPGs (McKeon et al., 1995; Bradbury et al., 2002; Davies et al., 2004; Grimpe and Silver, 2004). To test whether the hit compounds could overcome CSPGmediated inhibition, we performed neurite growth experiments using CGNs grown on a mixture of inhibitory CSPGs (Ernst et al., 

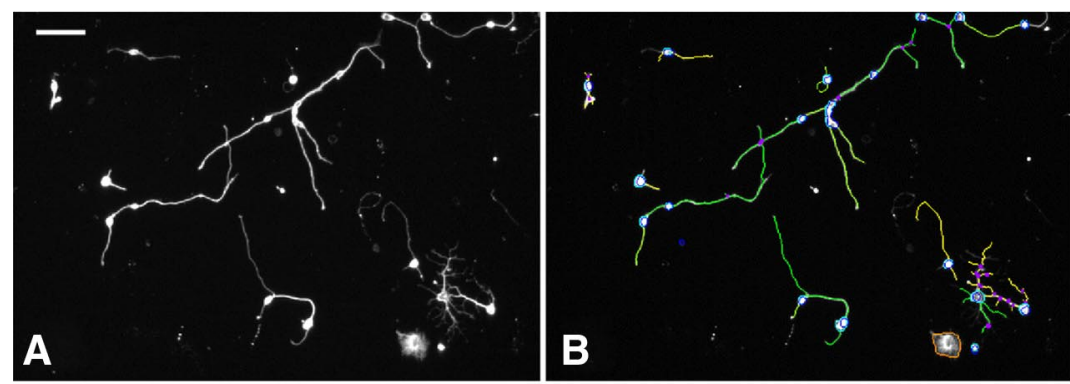
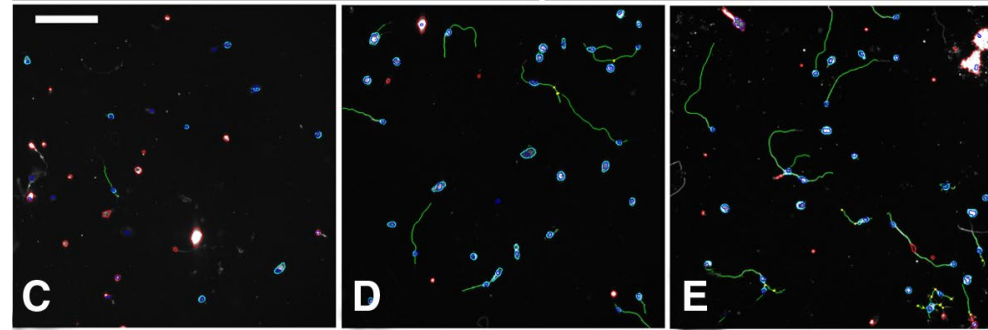

$\mathbf{F}$

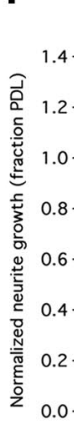

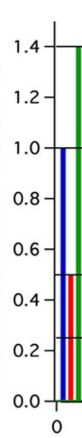

*<smiles>C1CC2CCC12</smiles>

* * $\quad$ *
H

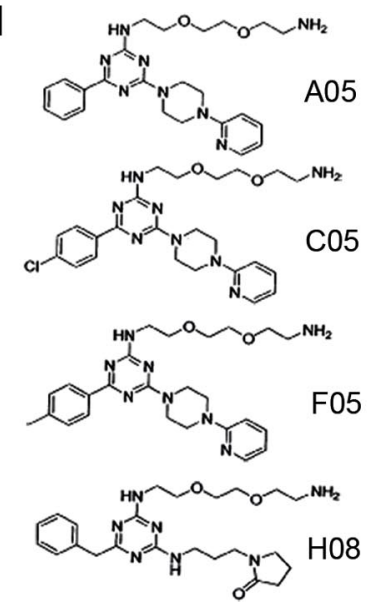

Figure 1. Identification of novel compounds overcoming inhibition. $A-E, P 8$ CGNs cultured on laminin for $2 \mathrm{~d}$ were stained for nuclei (Hoechst) and neurites (anti- $\beta$-tubulin), and then imaged using the Cellomics KSR. A, Raw image from the anti-tubulin channel; neurons with long processes are visible. $\boldsymbol{B}$, Computer analysis of the same field using the Neuronal Profiler bioapplication. Neurons are blue, a rejected cell is orange (bottom right), neurites are green and yellow, and cross points/branch points are purple. Neurons and their processes are well identified. C, Computer image of CGNs cultured on a myelin substrate. $D$, CGNs cultured on myelin in the presence of dbcAMP. Process growth is increased. $E$, CGNs cultured on myelin in the presence of hit compound A05 (5 $\mu \mathrm{m})$. Process outgrowth is similar to that seen with dbcAMP. Scale bars: $\boldsymbol{A}, \boldsymbol{B}, 50 \mu \mathrm{m} ; \boldsymbol{C}-\boldsymbol{E}, 100 \mu \mathrm{m}$. $\boldsymbol{F}$, Novel compound screen. Total neurite growth (normalized to the PDL control) is shown for 315 of the 400 compounds tested at a concentration of $5 \mu \mathrm{m}$. The first three bars show growth on PDL (blue), PDL/myelin (red), and PDL/myelin/dbcAMP (green). Myelin strongly reduced growth, and this was overcome by increasing cAMP. The straight lines drawn across graph represent (from top to bottom, respectively) growth levels with dbcAMP, PDL, myelin, and 50\% of the myelin level. A number of compounds either had little effect on growth at the concentration tested or decreased growth substantially; four of the test compounds (asterisks) reversed growth inhibition to an extent comparable with that seen with dbcAMP. The four asterisks, from left to right, correspond to H08, $\mathrm{CO5}$, F05, and A05. G, Dose-response relationships for the hit compounds on myelin. CGNs were cultured on PDL (horizontal bar) or on myelin in the presence of the four hit compounds at concentrations ranging from 10 nm to $5 \mu \mathrm{m}$ (note log scale on $x$-axis). Growth on myelin in the absence of compounds was set at 100\% (origin of $y$-axis). The Extended Neurite Outgrowth bioapplication was used to evaluate total neurite length perneuron. Each compound completely reversed growth inhibition by the myelin. $\mathrm{EC}_{50}$ concentrations werecalculated using lgor Pro (Wavemetrics) and were estimated to be $25 \mathrm{~nm}(\mathrm{A05}), 14 \mathrm{~nm}(\mathrm{CO5}), 9 \mathrm{~nm}(\mathrm{F05})$, and $15 \mathrm{~nm}$ (H08). Data points are averages of two independent experiments. $\boldsymbol{H}$, Structures of the four hit compounds. Compounds A05, C05, and F05 are closely related.

1995; Monnier et al., 2003). The CSPG mixture strongly inhibited laminin-mediated growth from CGNs (Fig. 2A). As expected from previous results (Sivasankaran et al., 2004), the PKC inhibitor 12-(2cyanoethyl)-6,7,12,13-tetrahydro-13-methyl-5-oxo-5H-indolo [2,3-a]pyrrolo[3,4-c]carbazole (Gö6976) restored the majority of growth inhibited by the CSPGs. Importantly, the hit compounds (1 $\mu \mathrm{M})$ were also capable of overcoming CSPG-mediated inhibition as effectively as the PKC inhibitor (Fig. 2A). Thus, the hit compounds we have identified can overcome both major types of inhibition found in the injured CNS: that from myelin debris and from the CSPGs found in the glial scar.

\section{Hit compounds overcome inhibition of a variety of} neuronal types

Our initial studies used CGNs, because they are a large population of relatively homogeneous neurons, which respond appro- priately to inhibitory substrates like myelin. However, other neuronal populations are arguably more relevant to CNS injury, and it is likely that different neuronal populations respond differently to inhibitory cues (Davies et al., 1999). We therefore tested the compounds on two other CNS populations-spinal cord neurons and cortical neurons. E14 rat spinal cord neurons responded well to LN substrates, growing as individual cells or small clumps of cells, with most having neurites (Fig. 2B). When added to the LN substrate, the CSPG mixture caused neurons to clump somewhat and strongly inhibited neuronal process formation (Fig. 2C). As was the case for CGNs, the PKC inhibitor Gö6976 partially reversed CSPG-mediated inhibition (Fig. 2D). Interestingly, all four hit compounds also reversed the inhibition of neurite growth, resulting in clumps of neurons with long processes extending from them (Fig. $2 E, F$ ). In fact, two 
of the hit compounds (F05, H08) were more effective at overcoming inhibition by CSPGs than was the PKC inhibitor, Gö6976 (Fig. 2F).

We also tested the ability of hit compounds to overcome inhibition of embryonic cortical neuron growth. In these experiments, we used only the CNS myelin substrate. Cortical neurons grew relatively well on PDL substrates; this growth was essentially nullified by addition of CNS myelin. Each of the four compounds overcame the inhibition by myelin, resulting in clear neurite growth on the PDL/ myelin substrate (supplemental Fig. 1, available at www.jneurosci.org as supplemental material). Together, our data demonstrate that these compounds can overcome multiple inhibitory signals in several different types of CNS neuron (see also Fig. 6).

The CGNs, spinal neurons, and cortical neurons we assayed came from immature tissue (embryonic or early postnatal). Clearly, it would be useful to know whether the compounds are also active on more mature neurons, as these respond differently to both stimulatory and inhibitory factors compared with immature neurons (Cohen et al., 1986; Tomaselli and Reichardt, 1988; Mukhopadhyay et al., 1994; Goldberg et al., 2002; Blizzard et al., 2007). To test whether the compounds are active on more mature neurons, we tested their ability to influence the growth of P20 rat RGCs. These neurons lose most of their capacity to regenerate during the first postnatal week, and RGCs older than P5 are mature with regard to regeneration capacity (Chen et al., 1995; Goldberg et al., 2002). As was the case for immature neurons, a mixed laminin/CSPG substrate strongly inhibited growth from P20 RGCs (Fig. 3A). In the presence of compound F05 $(1 \mu \mathrm{M})$, many RGCs grew longer processes (Fig. 3B). Quantitative analysis revealed that all four compounds were capable of improving regeneration of P20 RGCs challenged with CSPG substrates, with F05 proving the most effective (Fig. $3 C$ ). The increase in neurite length was not limited to a subpopulation, as the entire neurite length distribution was shifted to longer neurites in the presence of F05 (Fig. $3 D$ ). Thus, our hit compounds can improve regeneration of P20 RGCs on an inhibitory CSPG substrate, suggesting that the ability of our compounds to overcome inhibition is not limited to neurons with high intrinsic growth abilities.

Hit compounds act on a complex cellular inhibitory substrate As is common practice, we used purified myelin or CSPG substrates to represent the inhibitory barriers found in the injured CNS. However, we also examined the activity of the hit compounds on a complex cellular substrate, which should mimic the injured CNS more closely and thus serve as a more stringent test. For this, we made use of an in vitro model of the glial scar that we recently developed (Wanner et al., 2008). The model consists of a culture of mature astrocytes challenged with two different injuryrelated stimuli: mechanical stretch insult and coculture with meningeal fibroblasts (see Materials and Methods). We have shown that each of these stimuli leads to the development of a "reactive" phenotype in astrocytes, production of several known regeneration-inhibitory proteins, and a strong decrease in the ability of neurons to grow neurites on the cultured astrocytes (Wanner et al., 2008). In particular, both P6 cortical neurons and large-diameter dorsal root ganglion neurons grow relatively poorly on the glial scar model compared with growth on control astrocytes. Thus, this culture model presents a complex scar-like environment with which to test the ability of our hit compounds to overcome regeneration inhibition. As expected, we found that postnatal cortical neurons (Fig. $4 \mathrm{~A}$ ) and large-diameter embryonic dorsal root ganglion neurons (Fig. $4 C$ ) grew relatively poorly on the in vitro scar model. The number of neurons with neurites decreased by $54 \%$ in cortical neurons cultured on the scar model compared with those on control astrocytes (Fig. 4E). Addition of compound F05 to neurons on the scar model nearly doubled the number of neurons with neurites, allowing growth similar to that seen on control astrocytes in the absence of F05 (Fig. 4B,E). The growth of dorsal root ganglion neurons on the scar model was also significantly increased by F05 (Fig. $4 D$ ); total neurite length increased by almost $50 \%$ (from $2295 \pm 276$ to $3355 \pm 226 \mu \mathrm{m}$; $p<0.003 ; N=23$ neurons/condition). Cultures stained for GFAP, tenascin, and CS56 (recognizes CSPGs) as markers of astrocyte reactivity showed no differences in staining intensity in control versus F05-treated cultures (data not shown). This observation suggests that $\mathrm{F} 05$ is acting directly on neurons rather than on the substrate cells. Thus, at least one of our hit compounds is capable of overcoming the inhibition of regeneration caused by this complex, scar-like cellular system. 

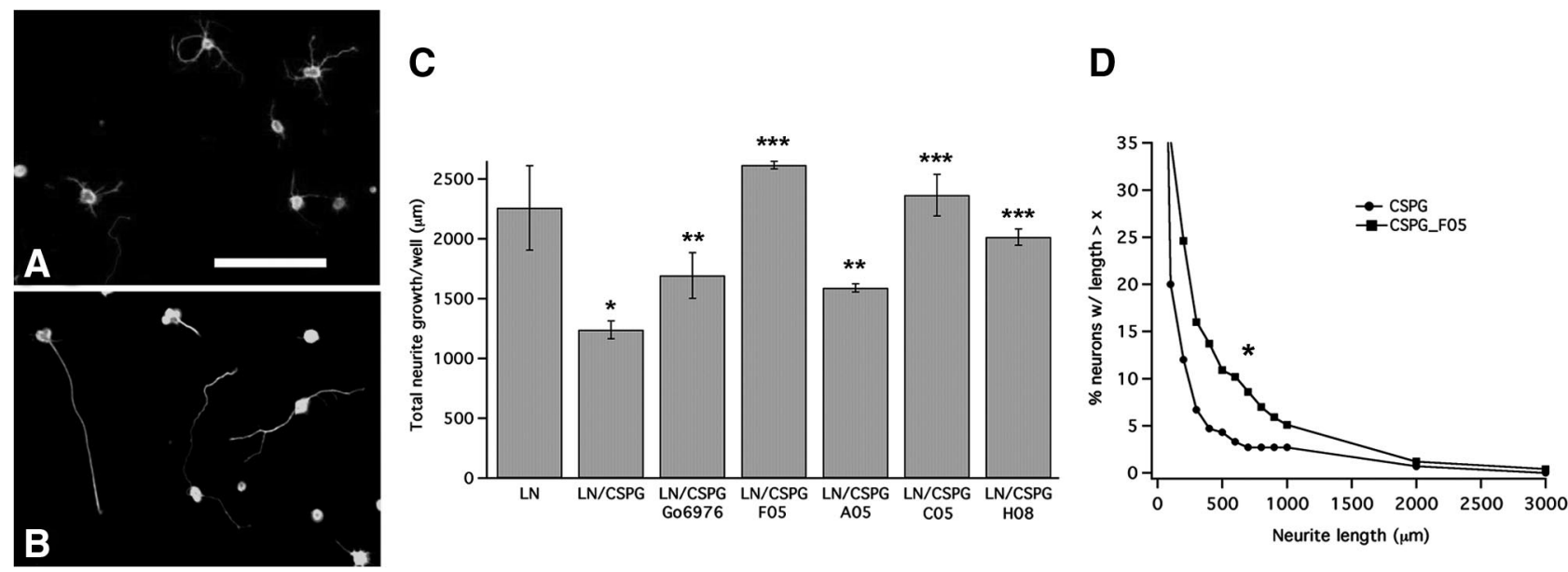

Figure 3. Hit compounds increase growth of mature RGCs on the CSPG mixture. P20 RGCs were cultured for $5 \mathrm{~d}$ on a LN/CSPG substrate, in the absence $(\boldsymbol{A})$ or presence $(\boldsymbol{B})$ of compound F05 at 1 $\mu \mathrm{M}$. F05 improved axon growth on the inhibitory substrate. Scale bar, $100 \mu \mathrm{m}$. C, Average total neurite growth/neuron, measured with Neurolucida, is plotted (mean \pm SEM) for a single experiment performed in triplicate in which all four hit compounds $(1 \mu \mathrm{M})$ and Gö6976 (100 nM) were tested on P20 RGCs. The CSPGs reduced neurite growth by $\sim 45 \%$. Growth was partially restored by the PKC inhibitor Gö6976 and by hit compound A05, and inhibition was reversed essentially completely by the other three hit compounds. At least 50 , and usually $>75$, neurons were analyzed per condition. The CSPG condition was significantly different from control ( $\left.{ }^{*} p<0.05\right)$, and all compound treatments were significantly different from CSPG alone $\left(^{* *} p<0.001, \mathrm{F05}, \mathrm{C05}, \mathrm{H} 08\right.$; ${ }^{* * *} p<0.01$, $\mathrm{G} 06976, \mathrm{A05}$ ). D. Cumulative neurite growth histogram for an experiment with F05 shows that the complete neurite length distribution was shifted to longer neurites in the presence of $\mathrm{F} 05$ ( $p<$ 0.001 , repeated-measures ANOVA). Similar results were obtained in a second experiment.
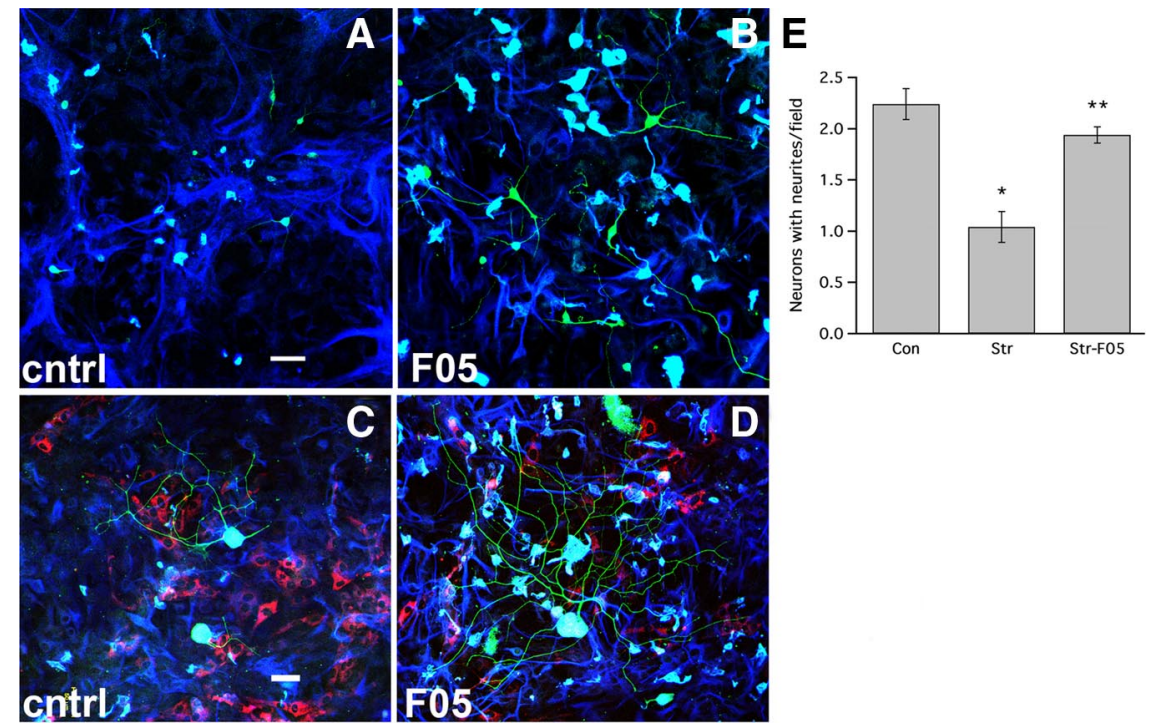

inhibitory signals. To distinguish between these possibilities, we examined the effects of the hit compounds on CGNs growing on two permissive substrates-PDL and $\mathrm{LN}$. The neurons grew on PDL substrates and grew much better on LN substrates, as expected (Fig. 5). However, addition of the hit compounds $(1 \mu \mathrm{M})$ did not improve growth on either substrate; in fact, growth on both substrates was slightly inhibited by one of the hit compounds (A05) (Fig. 5). The failure of the hit compounds to increase growth on permissive substrates was not attributable to saturation of the growth response, as growth of the neurons on LN was significantly improved by addition of the CPKC inhibitor, Gö6976 (Sivasankaran et al., 2004). These data indicate that the hit compounds are not general promoters of neurite growth

Figure 4. Compound F05 increases growth on a model of the glial scar. $A, B$, Neurons from P6 sensorimotor cortex were dissociated and plated onto stretched astrocyte-fibroblast cocultures (scar model) for $24 \mathrm{~h}$ before fixation and staining for GFAP (dark blue), $\beta 3$ tubulin (light blue), and Ctip2 (green) in the presence $(\boldsymbol{B})$ or absence $(\boldsymbol{A})$ of $1 \mu \mathrm{m}$ F05. [Ctip2 is expressed by a subpopulation of cortical neurons including projection neurons (Arlotta et al., 2005).] Neurite growth is increased in the presence of F05. C, D, E17 dorsal root ganglion neurons were precultured with FUdR (fluorodeoxyuridine) for 2 weeks to kill Schwann cells, and then removed and seeded with (D) or without $(\boldsymbol{C}) 1 \mu \mathrm{m}$ F05 onto the scar model (stretched astrocyte/fibroblast cocultures) for $24 \mathrm{~h}$. Cultures were fixed and stained for GFAP (blue), fibronectin (red), and $\beta 3$-tubulin (green). Neurons grew markedly longer neurites in the presence of $\mathrm{F} 05$ (see text for quantification). Note intense GFAP staining of reactive astrocytes mingled with red fibroblasts. Scale bars, $50 \mu \mathrm{m}$. $E$, Number of neurons with neurites per microscope field, for a single experiment with $\mathrm{P} 6$ cortical neurons performed in triplicate. An average of 235 fields was assessed for each condition. Neurite growth was reduced on the stretch-activated astrocytes (Str), and this effect was mostly reversed by F05 $(1 \mu \mathrm{M})$. *Significantly different from control astrocytes $(p<0.001) .{ }^{* *}$ Significantly different from stretched astrocytes without F05 $(p<0.01)$. Error bars indicate SEM.

\section{Hit compounds selectively overcome inhibition}

The hit compounds we have identified act on a variety of neuronal types facing several distinct classes of inhibitory signal. Thus, they appear to be acting on relatively general neurite outgrowth signaling pathways. In principle, the hit compounds could be acting either as general promoters of neurite outgrowth (regardless of substrate), or they could be acting selectively to overcome and strongly suggest that they act selectively by interfering with general inhibitory signaling pathways.

\section{Lack of activity of hit compounds on cAMP, cPKC, and EGFR}

Several signaling pathways have been implicated in the mechanisms of inhibition by glial-derived inhibitors; studies of myelin-associated inhibitory proteins have mostly focused on cAMP. The developmental loss of the ability of CNS neurons to regenerate on myelin appears to involve a decrease in cAMP levels (Cai et al., 2001), and elevation of cAMP via addition of membrane-permeable dbcAMP, addition of forskolin, or inhibition of phosphodiesterase can block myelin-mediated neurite growth inhibition (Hannila and Filbin, 2008). To investigate whether the hit compounds act by increasing cAMP, we mea- 


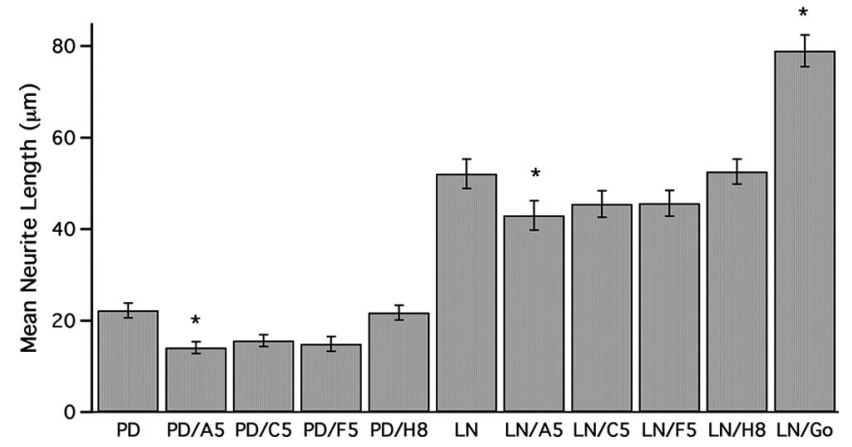

Figure 5. The hit compounds do not increase neurite growth on permissive substrates. CGNs were cultured on PDL or LN substrates in the absence or presence of the four hit compounds, or on LN in the presence of Gö6976 (Go). Data are plotted as mean \pm SEM for two independent experiments performed in quadruplicate. Neurons grew neurites on PDL and longer neurites on $\mathrm{LN}$. None of the hit compounds increased neurite growth on either substrate, and the A05 compound (A5) slightly decreased growth. In contrast, the PKC inhibitor significantly increased growth on LN, suggesting that the hit compounds do not act by inhibiting CPKC. *Significantly different from control, $p<0.05$.

sured levels of cAMP in CGNs grown on myelin substrates in the presence and absence of the four hit compounds, using forskolin as a positive control. Neuronal cAMP levels were measured after 2 and $48 \mathrm{~h}$. Untreated CGNs grown either on myelin or on PDL had low levels of cAMP. As expected, neurons treated with forskolin had levels of cAMP 50- to 125-fold greater than levels observed in untreated cells (supplemental Fig. 2, available at www. jneurosci.org as supplemental material). In contrast, neurons treated with each of the four hit compounds $(1 \mu \mathrm{M})$ showed no significant increase in CAMP, yet inhibition by myelin was overcome. Thus, the hit compounds do not act by elevating cAMP.

Results of a regeneration-based screen of known bioactive compounds have implicated cPKC- and EGFR-mediated signaling events in the activities of glial-derived inhibitors (Sivasankaran et al., 2004; Koprivica et al., 2005; Ahmed et al., 2009). In particular, inhibition of PKC, or of the EGFR, blocked the neurite-inhibitory effects of both myelin and CSPGs. We tested whether the hit compounds were acting through inhibition of the EGFR, first using an in-cell activity assay to assess EGFR phosphorylation in A431 cells. Cells were stimulated with EGF in the presence or absence of the hit compounds, or of the EGFR inhibitor PD168393 as a positive control. Phosphorylation of EGFR in untreated cells was increased by EGF, and this increase was completely blocked by PD168393. However, none of the four hit compounds decreased EGF-stimulated EGFR phosphorylation at concentrations up to $1 \mu \mathrm{M}$ (supplemental Fig. $3 A$, available at www.jneurosci.org as supplemental material). To test whether EGFR activation in neurons was inhibited by F05, we stimulated EGFR activity in CGNs in the presence and absence of $1 \mu \mathrm{M}$ F05; F05 also had no effect in this case (supplemental Fig. 3B, available at www.jneurosci.org as supplemental material). Indeed, a fulldose-response curve indicates that the concentration dependence of EGFR activation is unchanged in the presence of F05 (supplemental Fig. 3C,D, available at www.jneurosci.org as supplemental material).

We then tested whether the hit compounds could directly inhibit $\mathrm{cPKC}$, using an in vitro biochemical assay to assess the levels of active (phosphorylated) PKC. As expected, calphostin C reduced $\mathrm{PKC}$ activity by $\sim 80 \%$ in this assay. At a concentration at which the hit compounds are maximally active when added to cells (100 nM), none of the compounds significantly decreased PKC activity when added directly to the purified enzyme. One of the compounds (A05) decreased PKC activity by $29 \%$ at a concentration of $1 \mu \mathrm{M}$, but the other hit compounds, including F05, did not substantially alter PKC activity even at this concentration (supplemental Fig. 4A, available at www.jneurosci.org as supplemental material). We also tested the ability of compound F05 to inhibit PKC in neurons. In these experiments, we saw that $1 \mu \mathrm{M}$ F05 had no effect on the level of PKC activation in CGNs (supplemental Fig. $4 B$, available at www.jneurosci.org as supplemental material). Inhibition of PKC, therefore, does not appear to be the mode of action of the compounds. In summary, our hit compounds (at least F05) appear to act through mechanisms that do not directly involve inhibition of cPKC or EGFR activation.

\section{F05 affects microtubule dynamics in neurons and non-neuronal cells}

Compounds with backbones similar to those of our hit compounds have been shown to bind tubulin and to dramatically shorten MTs in myotubes and in fibroblastic cells (Duckmanton et al., 2005; Kim et al., 2006). We therefore investigated whether one of the hit compounds (F05) was capable of shortening MTs in fibroblastic cells. A concentration of F05 that provides maximal increases in neurite regeneration $(1 \mu \mathrm{M})$ did not shorten or sever MTs in COS cells grown on PDL substrates (Fig. 6D, F). In fact, F05 increased tubulin staining, with a clear increase in MT density in the COS cells. F05 treatment led to an increase in staining intensity for both dynamic (tyrosinated) MTs and for total MTs (Fig. 6C,F).

To test whether these F05-induced changes in MT dynamics also occurred in neurons, we examined MTs in growth cones and distal axons of hippocampal neurons grown on inhibitory CSPG substrates. Hippocampal neurons were chosen because they have well defined axons with large growth cones. Preliminary experiments demonstrated that axon growth from embryonic hippocampal neurons, like other neuronal types, can be inhibited by the CSPG mixture (supplemental Fig. 5, available at www. jneurosci.org as supplemental material). In hippocampal neurons, F05 treatment appeared to lead to an increase in levels of both acetylated (stable) MTs and tyrosinated (dynamic) MTs (Fig. 6). In addition, F05 treatment led to a splaying out of dynamic MTs into the growth cone periphery (Fig. $6 \mathrm{H}, \mathrm{L}$ ) and an apparent enlargement of growth cone area (Fig. $6 G, K$ ). For comparison, we examined MT staining in neurons treated with a known MT stabilizer (Taxol) and with a ROCK inhibitor $[(R)$ (+)-trans- $N$-(4-pyridyl)-4-(1-aminoethyl)-cyclohexanecarboxamide (Y27632)] that is known to overcome CSPG-mediated inhibition (Monnier et al., 2003). Taxol dramatically decreased staining for tyrosinated tubulin and increased staining for acetylated tubulin, as expected (Fig. 6O-R). Y27632, in contrast, did not appear to alter MT staining (images not shown).

To quantify these observations, we measured growth cone area, as well as staining intensity for tyrosinated and acetylated MTs in the growth cone and distal axon. F05 significantly increased growth cone area (by 40\%), whereas neither Taxol nor the ROCK inhibitor had any effect (Fig. 6S). Furthermore, F05 increased acetylated MT density by $>60 \%$, and Taxol increased this density by threefold, whereas Y27632 had no effect (Fig. 6T). Interestingly, whereas Taxol decreased tyrosinated MT density by $80 \%$, F05 slightly increased this density (by 30\%). Y27632 again had no effect (Fig. 6U). In summary, F05 alters growth cone MT dynamics and alters growth cone shape. Although F05 does stabilize MTs, its mechanism of action appears somewhat distinct from that of Taxol. Furthermore, F05 appears to act by a mechanism distinct from that of the Rho/ROCK pathway; the ROCK 


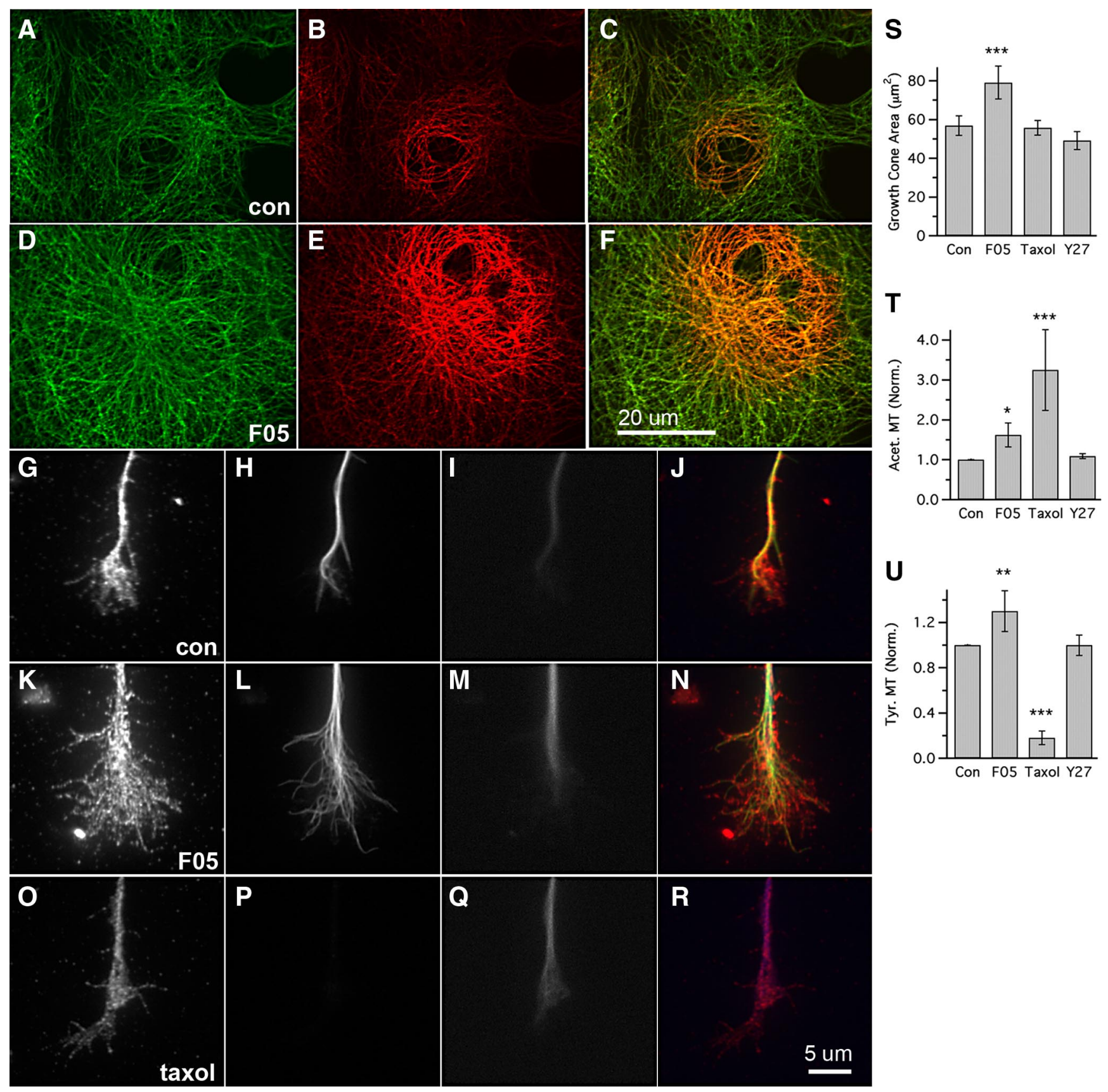

Figure 6. F05 increases MT density and levels of both dynamic and static MTs. $A-F$, COS cells were treated with vehicle $(\boldsymbol{A}-\boldsymbol{C})$ or with F05 $(1 \mu \mathrm{M})(\boldsymbol{D}-\boldsymbol{F})$ for $1 \mathrm{~h}$ before fixation and staining for total $\beta$-tubulin (green) and tyrosinated $\alpha$-tubulin (red). The densities of both total MTs (D) and dynamic MTs ( $\boldsymbol{E})$ appeared to increase with F05 treatment. $\mathbf{G}-\boldsymbol{R}$, Hippocampal neurons (48 $\mathrm{h}$ in culture) were treated with vehicle $(\mathbf{G}-\boldsymbol{J}), 1 \mu \mathrm{m}$ F05 $(\boldsymbol{K}-\boldsymbol{N})$, or $5 \mu \mathrm{m}$ Taxol $(\mathbf{O}-\boldsymbol{R})$. After $1 \mathrm{~h}$, cells were stained for GAP-43 $(\mathbf{G}, \boldsymbol{K}, \mathbf{0})$, tyrosinated $\alpha$-tubulin (dynamic MTs) $(\boldsymbol{H}, \boldsymbol{L}, \mathbf{P})$, and acetylated $\alpha$-tubulin (stable MTs) $(\boldsymbol{I}, \mathbf{M}, \mathbf{Q})$, and growth cones and distal axons were imaged. GAP-43, tyrosinated MT, and acetylated MTs are shown in red, green, and blue, respectively, in $\boldsymbol{J}, \boldsymbol{N}$, and $\boldsymbol{R}$. Images were acquired with the same settings for each condition to allow direct comparison of intensities. S-U, Growth cone areas and MT densities (in growth cones and distal axons) were quantified in cultures treated with vehicle, F05 $(1 \mu \mathrm{M})$, Taxol $(5 \mu \mathrm{M})$, and the ROCK inhibitor Y27632 (10 $\mu \mathrm{M})$. A total of 90-150 growth cones per condition were imaged; mean \pm SEM is shown for three to six independent experiments. S, F05 increased average growth cone area by 40\%; neither Taxol nor Y27632 changed growth cone area. $I$, F05 increased acetylated MT density by $60 \%$, and Taxol increased it by threefold, whereas Y 27632 had no effect. $\boldsymbol{U}$, F05 increased tyrosinated MT density by $30 \%$, whereas Taxol decreased this parameter by $80 \%$. Y 27632 had no effect. ${ }^{*} p<0.05 ;{ }^{* *} p<0.01 ;{ }^{* * *} p<0.001$.

inhibitor Y27632 affected neither growth cone area nor MT density. Clearly, F05 does not act by shortening MTs (unlike the purine-based compound myoseverin). More interestingly, our observations suggest a potential way in which the F05's activities may be translated into increased growth on inhibitory substrates. Changes in MT dynamics are expected to alter the ability of growth cones to respond to regeneration-inhibitory cues (Challacombe et al., 1997; Dent and Gertler, 2003; Ertürk et al., 2007).
F05 promotes acute regeneration of dorsal column axons F05 and the other hit compounds can overcome a variety of regeneration-inhibitory cues in vitro. To determine whether compound F05 is capable of overcoming inhibition of regeneration in vivo, we took advantage of an assay testing acute regeneration of dorsal column axons in mice expressing green fluorescent protein (GFP) in a subpopulation of sensory neurons (Ertürk et al., 2007). In these mice, dorsal column axons, which 
comprise the central processes of sensory neurons, can be imaged in live animals. After a superficial dorsal transection, the axons normally retract from the lesion site and mainly remain retracted for the next 48 h (Fig. 7 E,F) (Ertürk et al., 2007). In many cases, the cut axons form retraction bulb-like structures (Fig. $7 F, I$, red arrows). Treatment of the lesioned area with F05, however, resulted in a reduction in the formation of retraction bulb-like structures (supplemental Fig. 6, available at www.jneurosci.org as supplemental material) and an increase in the distances that axons were able to grow. Overall, the percentage of injuries with an axon growing past the midpoint of the original lesion site was just $8 \%$ ( 1 of 12 ) for control lesions and $61 \%$ (8 of 13) for lesions treated with F05 (Fig. 7G). In fact, some F05-treated axons could be observed crossing the lesion, growing for hundreds of micrometers past the cut site (Fig. 7C,H, green arrows). Thus, F05 can promote the regeneration of $\mathrm{CNS}$ axons in vivo.

\section{F05 potentiates regeneration of optic nerve axons}

Although our results with dorsal column axons demonstrate that F05 can promote regeneration in vivo, this assay is short term, and the inhibitory barrier has not fully formed at the time of examination (Jones et al., 2003). To test the ability of F05 to promote regeneration in a longer-term injury model, we turned to an optic nerve crush injury. After a complete crush of the adult rat optic nerve, many RGCs die, and there is little if any regeneration of optic axons past the crush site. Intraocular injection of CNTF increases RGC survival and provides limited regeneration (Park et al., 2004; Leaver et al., 2006; Hu et al., 2007; Lingor et al., 2008). Because F05 does not appear to increase survival in vitro (data not shown), we examined the ability of F05 to synergize with this survival-promoting treatment, by treating injured RGCs with CNTF in the presence or absence of F05. When animals were examined 2 weeks after nerve crush, we found that CNTF allowed a small degree of optic nerve regeneration, and this regeneration was enhanced by F05 treatment (Fig. 8A). Quantification revealed that F05 treatment increased the average length of the longest regenerating axon by $56 \%$ (from $780 \pm 101$ to $1220 \pm 118$ $\mu \mathrm{m} ; p<0.02 ; N=6$ animals/group) and led to an increased number of regenerating axons at each distance measured (Fig. $8 B$ ). Thus, F05 potentiates regeneration of adult optic nerve axons after a crush injury.

\section{Discussion}

Using a phenotypic screening approach with a novel chemical library, we identified four novel compounds that allowed neurons to grow neurites on an inhibitory myelin substrate. The compounds were potent, with estimated $\mathrm{EC}_{50}$ values in the nanomolar range. They promoted neurite growth from spinal cord, cortical, dorsal root ganglion, and retinal neurons as well as CGNs and, importantly, were active on older retinal ganglion cells. The compounds overcame inhibition not only from myelin but also from a mixture of inhibitory CSPGs, and from an in vitro model of the glial scar. Most significantly, one of the compounds (F05) was able to promote regeneration of dorsal column axons into and through a lesion of the spinal cord and to potentiate regeneration of optic nerve axons. We do not know the precise mechanism(s) through which the compounds are acting, but our data indicate that they selectively interfere with inhibitory signaling and that they regulate MT dynamics to stabilize MTs. Our compounds join a very short list of small molecules shown to overcome neurite inhibition on a variety of substrates and to promote regeneration in vivo. Because the compounds we identified are drug-like in structure, they have potential to lead to novel therapies for CNS injury or disease.

What is the rationale for our screening approach? First, although enormous progress has been made in understanding regeneration inhibition and potential therapeutic strategies, there are currently no treatments that promote robust regeneration of descending axon tracts. A number of myelin-based inhibitors (Domeniconi and Filbin, 2005) and inhibitory proteins of the glial scar (Miranda et al., 1999; Niederost et al., 1999; Pesheva and Probstmeier, 2000; Moreau-Fauvarque et al., 2003; Benson et al., 2005; Irizarry-Ramírez et al., 2005; Fabes et al., 2006) have been identified, and, for myelin in particular, several receptor components have also been identified (Wang et al., 2002; Mi et al., 2004; Park et al., 2005; Shao et al., 2005; Venkatesh et al., 2005; Atwal et al., 2008; Williams et al., 2008). However, it is unlikely that the full complement of glial-derived inhibitors is known, and we are just beginning to learn about the receptor mechanisms used by 
A

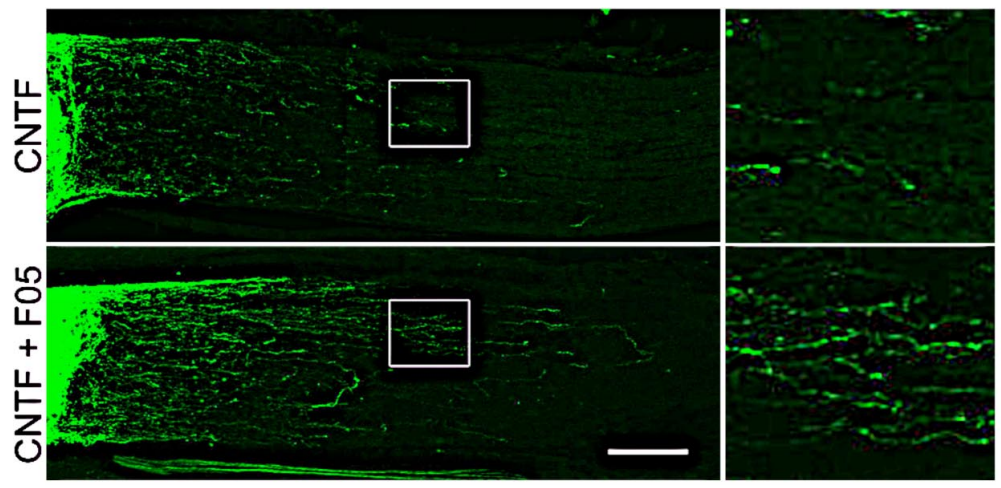

B

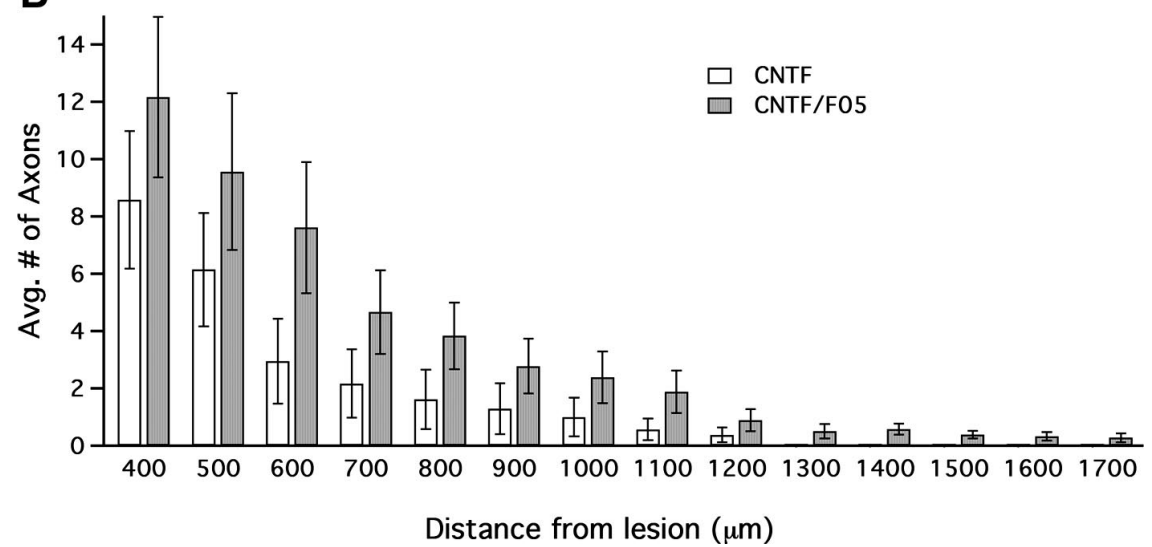

Figure 8. F05 promotes optic nerve regeneration. Optic nerves were crushed in adult rats, and F05- or vehicle-embedded Elvax was placed at the crush site before closing the wound. CNTF plus either vehicle or F05 were injected intravitreally at the time of surgery, and again at days 3,7 , and 10 after surgery. Fluorescent cholera toxin B (injected $24 \mathrm{~h}$ before kill) was used to trace regenerating axons. $A$, Some regeneration is visible in nerves treated with CNTF alone (top), but more, longer regenerating fibers are apparent in the CNTF plus F05 nerve. The insets at right are magnifications of the boxed areas in the left-hand images and show the highest density of fibers present at $1 \mathrm{~mm}$ from the crush sites. $\boldsymbol{B}$. The average number of axons in a section is plotted against distance from the crush site. F05 led to an increase in axon density at all distances measured; the two distributions differ significantly ( $p<0.001$, Wilcoxon's matched pairs $t$ test). Error bars indicate SEM. Scale bar, $200 \mu \mathrm{m}$.

inhibitory CSPGs (Shen et al., 2009). Therefore, we do not know the number or identity of potential targets for intervention in this process. We hypothesized that distinct inhibitory ligands and their neuronal receptors would eventually converge on common intracellular pathways responsible for regeneration inhibition. If so, such signaling nodes would be potential targets for chemical compounds, which could be found most easily by screening.

Our chemical screen is similar in design to that performed by He and colleagues (Sivasankaran et al., 2004; Koprivica et al., 2005) using a library of bioactive compounds with known targets. However, we chose to screen a novel library of compounds with unknown biological activities. The advantage of this approach relates to the mismatch between the large chemical space (number and structural types of chemical compounds) available and the relatively small number of proteins currently targeted by small molecules (likely $<5 \%$ of the proteome). Screening a library of novel compounds, unlike a library of known bioactives, has the potential to identify new targets. The disadvantage of our screen, of course, is that additional work is required to identify the target(s) and mechanism(s) of action of the hits.

We do not yet know the mechanisms through which our hit compounds overcome inhibition. Initial attempts at a candidate approach proved mostly negative- the compounds did not affect cAMP levels, or the activities of PKC, EGFR, ERK (extracellular signal-regulated kinase)/MAPK (mitogen-activated protein ki- nase) (data not shown), or Src family kinases (data not shown). In addition, F05 acts differently in the MT assay than other known small molecules overcoming regeneration inhibition (Taxol and Y27632), one of which (Y27632) targets the Rho/ ROCK pathway. These observations suggest that the compounds may have novel mechanisms of action. We are currently investigating this issue by overexpression/ knockdown screens to examine genes conferring sensitivity to F05 and by examination of global changes in expression of genes/proteins on microarrays.

Our hit compounds are functional when neurons are challenged with myelin, with a mixture of CSPGs, or with a cell culture model of the glial scar. Some signaling pathways appear to be common to CSPG and myelin inhibition, including signals through $\mathrm{cPKC}$, RhoA/ROCK, and possibly Akt/mTOR (mammalian target of rapamycin) (Powell et al., 2001; Monnier et al., 2003; Sivasankaran et al., 2004; Koprivica et al., 2005; Park et al., 2008). However, some results depend critically on the substrate used. For example, the activation state of integrin receptors significantly affects the results of inhibitory signaling interventions (Zhou et al., 2006). To some extent, signaling mechanisms underlying inhibition by CSPGs appear to differ from those underlying myelin inhibition (Zhou et al., 2006). Identification of the mechanism(s) of action of our hit compounds should provide insight into the signaling pathways common to different inhibitory proteins.

A screen of a triazine library similar to ours, using zebrafish morphogenesis as an assay, identified three disruptors of MTs (Moon et al., 2002). Our hit compounds do not appear to disrupt MTs, but they do affect MT dynamics in cultured cells, including an increase in stable MTs and a smaller increase in dynamic MTs. This is of interest because regeneration-inhibitory signals, whatever their nature, must ultimately regulate cytoskeletal dynamics, including those of MTs. For growth to proceed, MTs must polymerize, depolymerize, and move; interference with these dynamics will inhibit axon growth (Dent and Gertler, 2003; Grenningloh et al., 2004). Interestingly, MT dynamics are particularly important in regeneration of mature neurons (Jones et al., 2006). Therefore, MT-interacting proteins such as collapsin response mediator proteins (CRMPs), MAPs (MT-associated proteins), and stathmins (e.g., stathmin, SCG10) may be critical elements of regeneration inhibition (Dent and Gertler, 2003; Arimura et al., 2005; Bondallaz et al., 2006; Morii et al., 2006). Signals that affect axon growth may act through phosphorylation of these MT-interacting proteins by kinases like GSK-3 $\beta$, ROCK, CDK5, Akt, and JNKs (c-Jun N-terminal kinases) (Grenningloh et al., 2004; Arimura et al., 2005; Zhou and Snider, 2005; Tararuk et al., 2006). Although specific links between glial-associated regeneration inhibition and MT dynamics have not been demonstrated, RhoA is known to regulate the MT-interacting CRMPs, which are involved in repellant guidance (Arimura et al., 2005; 
Alabed et al., 2007). Interestingly, modification of MT dynamics can affect both retraction bulb formation and regeneration (Ertürk et al., 2007; Kamber et al., 2009). In fact, stabilization of MTs with Taxol can improve regeneration of dorsal column axons (Ertürk et al., 2007) and can increase growth of neurons on myelin and CSPG substrates (Ertürk et al., 2007). Whether the ability of F05 to affect MT dynamics is responsible for its ability to overcome inhibition remains to be investigated.

Our experiments on dorsal column and optic nerve axons show that at least one of our hit compounds is active in vivo, when applied directly to injured neurons and their axons. One major question is whether regeneration of other axonal populations, and descending spinal tracts in particular, can be improved with our compounds. Another important issue, both experimentally and (potentially) therapeutically, is the bioavailability of these compounds. The compounds might be effective when delivered, for example, intravenously, since they follow Lipinski's rules for drug-like compounds (Lipinski et al., 2001). Preliminary data show that F05, at least, can cross the blood-brain barrier (data not shown). We are currently investigating these questions.

In summary, we have screened a novel chemical library, identifying four hit compounds that can act to promote growth on a variety of neurons and inhibitory substrates. These compounds should provide insight into inhibitory signaling mechanisms and help lead to new therapeutic approaches.

\section{References}

Ahmed Z, Jacques SJ, Berry M, Logan A (2009) Epidermal growth factor receptor inhibitors promote CNS axon growth through off-target effects on glia. Neurobiol Dis 36:142-150.

Alabed YZ, Pool M, Ong Tone S, Fournier AE (2007) Identification of CRMP4 as a convergent regulator of axon outgrowth inhibition. J Neurosci 27:1702-1711.

Arimura N, Ménager C, Kawano Y, Yoshimura T, Kawabata S, Hattori A, Fukata Y, Amano M, Goshima Y, Inagaki M, Morone N, Usukura J, Kaibuchi K (2005) Phosphorylation by Rho kinase regulates CRMP-2 activity in growth cones. Mol Cell Biol 25:9973-9984.

Arlotta P, Molyneaux BJ, Chen J, Inoue J, Kominami R, Macklis JD (2005) Neuronal subtype-specific genes that control corticospinal motor neuron development in vivo. Neuron 45:207-221.

Atwal JK, Pinkston-Gosse J, Syken J, Stawicki S, Wu Y, Shatz C, TessierLavigne M (2008) PirB is a functional receptor for myelin inhibitors of axonal regeneration. Science 322:967-970.

Barres BA, Silverstein BE, Corey DP, Chun LL (1988) Immunological, morphological, and electrophysiological variation among retinal ganglion cells purified by panning. Neuron 1:791-803.

Benson MD, Romero MI, Lush ME, Lu QR, Henkemeyer M, Parada LF (2005) Ephrin-B3 is a myelin-based inhibitor of neurite outgrowth. Proc Natl Acad Sci U S A 102:10694-10699.

Blizzard CA, Haas MA, Vickers JC, Dickson TC (2007) Cellular dynamics underlying regeneration of damaged axons differs from initial axon development. Eur J Neurosci 26:1100-1108.

Bondallaz P, Barbier A, Soehrman S, Grenningloh G, Riederer BM (2006) The control of microtubule stability in vitro and in transfected cells by MAP1B and SCG10. Cell Motil Cytoskeleton 63:681-695.

Bradbury EJ, Moon LD, Popat RJ, King VR, Bennett GS, Patel PN, Fawcett JW, McMahon SB (2002) Chondroitinase ABC promotes functional recovery after spinal cord injury. Nature 416:636-640.

Bradke F, Dotti CG (1997) Neuronal polarity: vectorial cytoplasmic flow precedes axon formation. Neuron 19:1175-1186.

Bundesen LQ, Scheel TA, Bregman BS, Kromer LF (2003) Ephrin-B2 and EphB2 regulation of astrocyte-meningeal fibroblast interactions in response to spinal cord lesions in adult rats. J Neurosci 23:7789-7800.

Bunge MB, Pearse DD (2003) Transplantation strategies to promote repair of the injured spinal cord. J Rehabil Res Dev 40:55-62.

Cai D, Qiu J, Cao Z, McAtee M, Bregman BS, Filbin MT (2001) Neuronal cyclic AMP controls the developmental loss in ability of axons to regenerate. J Neurosci 21:4731-4739.

Challacombe JF, Snow DM, Letourneau PC (1997) Dynamic microtubule ends are required for growth cone turning to avoid an inhibitory guidance cue. J Neurosci 17:3085-3095.

Chen DF, Jhaveri S, Schneider GE (1995) Intrinsic changes in developing retinal neurons result in regenerative failure of their axons. Proc Natl Acad Sci U S A 92:7287-7291.

Cheng L, Itoh K, Lemmon V (2005) L1-mediated branching is regulated by two ezrin-radixin-moesin (ERM)-binding sites, the RSLE region and a novel juxtamembrane ERM-binding region. J Neurosci 25:395-403.

Cohen J, Burne JF, Winter J, Bartlett P (1986) Retinal ganglion cells lose response to laminin with maturation. Nature 322:465-467.

Colman DR, Kreibich G, Frey AB, Sabatini DD (1982) Synthesis and incorporation of myelin polypeptides into CNS myelin. J Cell Biol 95:598-608.

Davies JE, Tang X, Denning JW, Archibald SJ, Davies SJ (2004) Decorin suppresses neurocan, brevican, phosphacan and NG2 expression and promotes axon growth across adult rat spinal cord injuries. Eur J Neurosci 19:1226-1242.

Davies SJ, Goucher DR, Doller C, Silver J (1999) Robust regeneration of adult sensory axons in degenerating white matter of the adult rat spinal cord. J Neurosci 19:5810-5822.

Dent EW, Gertler FB (2003) Cytoskeletal dynamics and transport in growth cone motility and axon guidance. Neuron 40:209-227.

Dergham P, Ellezam B, Essagian C, Avedissian H, Lubell WD, McKerracher L (2002) Rho signaling pathway targeted to promote spinal cord repair. J Neurosci 22:6570-6577.

De Winter F, Oudega M, Lankhorst AJ, Hamers FP, Blits B, Ruitenberg MJ, Pasterkamp RJ, Gispen WH, Verhaagen J (2002) Injury-induced class 3 semaphorin expression in the rat spinal cord. Exp Neurol 175:61-75.

Domeniconi M, Filbin MT (2005) Overcoming inhibitors in myelin to promote axonal regeneration. J Neurol Sci 233:43-47.

Duckmanton A, Kumar A, Chang YT, Brockes JP (2005) A single-cell analysis of myogenic dedifferentiation induced by small molecules. Chem Biol 12:1117-1126.

Ernst H, Zanin MK, Everman D, Hoffman S (1995) Receptor-mediated adhesive and anti-adhesive functions of chondroitin sulfate proteoglycan preparations from embryonic chicken brain. J Cell Sci 108:3807-3816.

Ertürk A, Hellal F, Enes J, Bradke F (2007) Disorganized microtubules underlie the formation of retraction bulbs and the failure of axonal regeneration. J Neurosci 27:9169-9180.

Fabes J, Anderson P, Yáñez-Muñoz RJ, Thrasher A, Brennan C, Bolsover S (2006) Accumulation of the inhibitory receptor EphA4 may prevent regeneration of corticospinal tract axons following lesion. Eur J Neurosci 23:1721-1730.

Fawcett JW, Asher RA (1999) The glial scar and central nervous system repair. Brain Res Bull 49:377-391.

Feng G, Mellor RH, Bernstein M, Keller-Peck C, Nguyen QT, Wallace M, Nerbonne JM, Lichtman JW, Sanes JR (2000) Imaging neuronal subsets in transgenic mice expressing multiple spectral variants of GFP. Neuron 28:41-51.

Fitch MT, Silver J (1997) Glial cell extracellular matrix: boundaries for axon growth in development and regeneration. Cell Tissue Res 290:379-384.

Goldberg JL, Klassen MP, Hua Y, Barres BA (2002) Amacrine-signaled loss of intrinsic axon growth ability by retinal ganglion cells. Science 296:1860-1864.

Goldberg JL, Vargas ME, Wang JT, Mandemakers W, Oster SF, Sretavan DW, Barres BA (2004) An oligodendrocyte lineage-specific semaphorin, Sema5A, inhibits axon growth by retinal ganglion cells. J Neurosci 24:4989-4999.

GrandPré T, Li S, Strittmatter SM (2002) Nogo-66 receptor antagonist peptide promotes axonal regeneration. Nature 417:547-551.

Grenningloh G, Soehrman S, Bondallaz P, Ruchti E, Cadas H (2004) Role of the microtubule destabilizing proteins SCG10 and stathmin in neuronal growth. J Neurobiol 58:60-69.

Grimpe B, Silver J (2004) A novel DNA enzyme reduces glycosaminoglycan chains in the glial scar and allows microtransplanted dorsal root ganglia axons to regenerate beyond lesions in the spinal cord. J Neurosci 24:1393-1397.

Hagino S, Iseki K, Mori T, Zhang Y, Hikake T, Yokoya S, Takeuchi M, Hasimoto H, Kikuchi S, Wanaka A (2003) Slit and glypican-1 mRNAs are coexpressed in the reactive astrocytes of the injured adult brain. Glia 42:130-138.

Hannila SS, Filbin MT (2008) The role of cyclic AMP signaling in promoting axonal regeneration after spinal cord injury. Exp Neurol 209:321-332. 
Houle JD, Tom VJ, Mayes D, Wagoner G, Phillips N, Silver J (2006) Combining an autologous peripheral nervous system "bridge" and matrix modification by chondroitinase allows robust, functional regeneration beyond a hemisection lesion of the adult rat spinal cord. J Neurosci 26:7405-7415.

Hu Y, Cui Q, Harvey AR (2007) Interactive effects of C3, cyclic AMP and ciliary neurotrophic factor on adult retinal ganglion cell survival and axonal regeneration. Mol Cell Neurosci 34:88-98.

Irizarry-Ramírez M, Willson CA, Cruz-Orengo L, Figueroa J, Velázquez I, Jones H, Foster RD, Whittemore SR, Miranda JD (2005) Upregulation of EphA3 receptor after spinal cord injury. J Neurotrauma 22:929-935.

Jones LL, Margolis RU, Tuszynski MH (2003) The chondroitin sulfate proteoglycans neurocan, brevican, phosphacan, and versican are differentially regulated following spinal cord injury. Exp Neurol 182:399-411.

Jones SL, Selzer ME, Gallo G (2006) Developmental regulation of sensory axon regeneration in the absence of growth cones. J Neurobiol 66:1630-1645.

Kamber D, Erez H, Spira ME (2009) Local calcium-dependent mechanisms determine whether a cut axonal end assembles a retarded endbulb or competent growth cone. Exp Neurol 219:112-125.

Kim YJ, Sackett DL, Schapira M, Walsh DP, Min J, Pannell LK, Chang YT (2006) Identification of 12Cysbeta on tubulin as the binding site of tubulyzine. Bioorg Med Chem 14:1169-1175.

Kim YK, Chang YT (2007) Tagged library approach facilitates forward chemical genetics. Mol Biosyst 3:392-397.

Koprivica V, Cho KS, Park JB, Yiu G, Atwal J, Gore B, Kim JA, Lin E, TessierLavigne M, Chen DF, He Z (2005) EGFR activation mediates inhibition of axon regeneration by myelin and chondroitin sulfate proteoglycans. Science 310:106-110.

Laabs TL, Wang H, Katagiri Y, McCann T, Fawcett JW, Geller HM (2007) Inhibiting glycosaminoglycan chain polymerization decreases the inhibitory activity of astrocyte-derived chondroitin sulfate proteoglycans. J Neurosci 27:14494-14501.

Leaver SG, Cui Q, Plant GW, Arulpragasam A, Hisheh S, Verhaagen J, Harvey AR (2006) AAV-mediated expression of CNTF promotes long-term survival and regeneration of adult rat retinal ganglion cells. Gene Ther 13:1328-1341.

Lee JW, Bork JT, Samanta A, Chang YT (2009) Novel orthogonal synthesis of tagged combinatorial triazine library via Grignard reaction. Aust J Chem 62:1000-1006.

Lehmann M, Fournier A, Selles-Navarro I, Dergham P, Sebok A, Leclerc N, Tigyi G, McKerracher L (1999) Inactivation of Rho signaling pathway promotes CNS axon regeneration. J Neurosci 19:7537-7547.

Li S, Liu BP, Budel S, Li M, Ji B, Walus L, Li W, Jirik A, Rabacchi S, Choi E, Worley D, Sah DW, Pepinsky B, Lee D, Relton J, Strittmatter SM (2004) Blockade of Nogo-66, myelin-associated glycoprotein, and oligodendrocyte myelin glycoprotein by soluble Nogo-66 receptor promotes axonal sprouting and recovery after spinal injury. J Neurosci 24:10511-10520.

Lingor P, Teusch N, Schwarz K, Mueller R, Mack H, Bähr M, Mueller BK (2007) Inhibition of Rho kinase (ROCK) increases neurite outgrowth on chondroitin sulphate proteoglycan in vitro and axonal regeneration in the adult optic nerve in vivo. J Neurochem 103:181-189.

Lingor P, Tönges L, Pieper N, Bermel C, Barski E, Planchamp V, Bähr M (2008) ROCK inhibition and CNTF interact on intrinsic signalling pathways and differentially regulate survival and regeneration in retinal ganglion cells. Brain 131:250-263.

Lipinski CA, Lombardo F, Dominy BW, Feeney PJ (2001) Experimental and computational approaches to estimate solubility and permeability in drug discovery and development settings. Adv Drug Deliv Rev 46:3-26.

Matsuura I, Taniguchi J, Hata K, Saeki N, Yamashita T (2008) BMP inhibition enhances axonal growth and functional recovery after spinal cord injury. J Neurochem 105:1471-1479.

McKeon RJ, Schreiber RC, Rudge JS, Silver J (1991) Reduction of neurite outgrowth in a model of glial scarring following CNS injury is correlated with the expression of inhibitory molecules on reactive astrocytes. J Neurosci 11:3398-3411.

McKeon RJ, Höke A, Silver J (1995) Injury-induced proteoglycans inhibit the potential for laminin-mediated axon growth on astrocytic scars. Exp Neurol 136:32-43.

McKerracher L, Higuchi H (2006) Targeting rho to stimulate repair after spinal cord injury. J Neurotrauma 23:309-317.

Meyer-Franke A, Kaplan MR, Pfrieger FW, Barres BA (1995) Characteriza- tion of the signaling interactions that promote the survival and growth of developing retinal ganglion cells in culture. Neuron 15:805-819.

Mi S, Lee X, Shao Z, Thill G, Ji B, Relton J, Levesque M, Allaire N, Perrin S, Sands B, Crowell T, Cate RL, McCoy JM, Pepinsky RB (2004) LINGO-1 is a component of the Nogo-66 receptor/p75 signaling complex. Nat Neurosci 7:221-228.

Min J, Kyung Kim Y, Cipriani PG, Kang M, Khersonsky SM, Walsh DP, Lee JY, Niessen S, Yates JR 3rd, Gunsalus K, Piano F, Chang YT (2007) Forward chemical genetic approach identifies new role for GAPDH in insulin signaling. Nat Chem Biol 3:55-59.

Miranda JD, White LA, Marcillo AE, Willson CA, Jagid J, Whittemore SR (1999) Induction of Eph B3 after spinal cord injury. Exp Neurol $156: 218-222$.

Miyashita T, Koda M, Kitajo K, Yamazaki M, Takahashi K, Kikuchi A, Yamashita T (2009) Wnt-Ryk signaling mediates axon growth inhibition and limits functional recovery after spinal cord injury. J Neurotrauma 26:955-964.

Monnier PP, Sierra A, Schwab JM, Henke-Fahle S, Mueller BK (2003) The Rho/ROCK pathway mediates neurite growth-inhibitory activity associated with the chondroitin sulfate proteoglycans of the CNS glial scar. Mol Cell Neurosci 22:319-330.

Moon HS, Jacobson EM, Khersonsky SM, Luzung MR, Walsh DP, Xiong W, Lee JW, Parikh PB, Lam JC, Kang TW, Rosania GR, Schier AF, Chang YT (2002) A novel microtubule destabilizing entity from orthogonal synthesis of triazine library and zebrafish embryo screening. J Am Chem Soc 124:11608-11609.

Moon LD, Asher RA, Rhodes KE, Fawcett JW (2001) Regeneration of CNS axons back to their target following treatment of adult rat brain with chondroitinase ABC. Nat Neurosci 4:465-466.

Moon LD, Asher RA, Fawcett JW (2003) Limited growth of severed CNS axons after treatment of adult rat brain with hyaluronidase. J Neurosci Res 71:23-37.

Moreau-Fauvarque C, Kumanogoh A, Camand E, Jaillard C, Barbin G, Boquet I, Love C, Jones EY, Kikutani H, Lubetzki C, Dusart I, Chédotal A (2003) The transmembrane semaphorin Sema4D/CD100, an inhibitor of axonal growth, is expressed on oligodendrocytes and upregulated after CNS lesion. J Neurosci 23:9229-9239.

Morii H, Shiraishi-Yamaguchi Y, Mori N (2006) SCG10, a microtubule destabilizing factor, stimulates the neurite outgrowth by modulating microtubule dynamics in rat hippocampal primary cultured neurons. J Neurobiol 66:1101-1114.

Mukhopadhyay G, Doherty P, Walsh FS, Crocker PR, Filbin MT (1994) A novel role for myelin-associated glycoprotein as an inhibitor of axonal regeneration. Neuron 13:757-767.

Niederöst BP, Zimmermann DR, Schwab ME, Bandtlow CE (1999) Bovine CNS myelin contains neurite growth-inhibitory activity associated with chondroitin sulfate proteoglycans. J Neurosci 19:8979-8989.

Norton WT, Poduslo SE (1973) Myelination in rat brain: method of myelin isolation. J Neurochem 21:749-757.

Park JB, Yiu G, Kaneko S, Wang J, Chang J, He XL, Garcia KC, He Z (2005) A TNF receptor family member, TROY, is a coreceptor with Nogo receptor in mediating the inhibitory activity of myelin inhibitors. Neuron 45:345-351.

Park K, Luo JM, Hisheh S, Harvey AR, Cui Q (2004) Cellular mechanisms associated with spontaneous and ciliary neurotrophic factor-cAMPinduced survival and axonal regeneration of adult retinal ganglion cells. J Neurosci 24:10806-10815.

Park KK, Liu K, Hu Y, Smith PD, Wang C, Cai B, Xu B, Connolly L, Kramvis I, Sahin M, He Z (2008) Promoting axon regeneration in the adult CNS by modulation of the PTEN/mTOR pathway. Science 322:963-966.

Pesheva P, Probstmeier R (2000) Association of tenascin-R with murine brain myelin membranes: involvement of divalent cations. Neurosci Lett 283:165-168.

Powell EM, Mercado ML, Calle-Patino Y, Geller HM (2001) Protein kinase C mediates neurite guidance at an astrocyte boundary. Glia 33:288-297.

Reier PJ, Houle JD (1988) The glial scar: its bearing on axonal elongation and transplantation approaches to CNS repair. Adv Neurol 47:87-138.

Rhine WD, Hsieh DS, Langer R (1980) Polymers for sustained macromolecule release: procedures to fabricate reproducible delivery systems and control release kinetics. J Pharm Sci 69:265-270.

Schnell L, Schneider R, Kolbeck R, Barde YA, Schwab ME (1994) 
Neurotrophin-3 enhances sprouting of corticospinal tract during development and after adult spinal cord lesion. Nature 367:170-173.

Schwab JM, Leppert CA, Kaps KH, Monnier PP (2001) Functional recovery after spinal cord injury: basic science meets clinic. Trends Neurosci 24:437-439.

Schwab JM, Conrad S, Monnier PP, Julien S, Mueller BK, Schluesener HJ (2005) Spinal cord injury-induced lesional expression of the repulsive guidance molecule (RGM). Eur J Neurosci 21:1569-1576.

Shao Z, Browning JL, Lee X, Scott ML, Shulga-Morskaya S, Allaire N, Thill G, Levesque M, Sah D, McCoy JM, Murray B, Jung V, Pepinsky RB, Mi S (2005) TAJ/TROY, an orphan TNF receptor family member, binds Nogo-66 receptor 1 and regulates axonal regeneration. Neuron 45:353-359.

Shen Y, Tenney AP, Busch SA, Horn KP, Cuascut FX, Liu K, He Z, Silver J, Flanagan JG (2009) PTPsigma is a receptor for chondroitin sulfate proteoglycan, an inhibitor of neural regeneration. Science 326:592-596.

Silver J, Miller JH (2004) Regeneration beyond the glial scar. Nat Rev Neurosci 5:146-156.

Sivasankaran R, Pei J, Wang KC, Zhang YP, Shields CB, Xu XM, He Z (2004) PKC mediates inhibitory effects of myelin and chondroitin sulfate proteoglycans on axonal regeneration. Nat Neurosci 7:261-268.

Tang X, Davies JE, Davies SJ (2003) Changes in distribution, cell associations, and protein expression levels of NG2, neurocan, phosphacan, brevican, versican $\mathrm{V} 2$, and tenascin-C during acute to chronic maturation of spinal cord scar tissue. J Neurosci Res 71:427-444.

Tararuk T, Ostman N, Li W, Björkblom B, Padzik A, Zdrojewska J, Hongisto V, Herdegen T, Konopka W, Courtney MJ, Coffey ET (2006) JNK1 phosphorylation of SCG10 determines microtubule dynamics and axodendritic length. J Cell Biol 173:265-277.

Tomaselli KJ, Reichardt LF (1988) Peripheral motoneuron interactions with laminin and Schwann cell-derived neurite-promoting molecules: developmental regulation of laminin receptor function. J Neurosci Res 21:275-285.
Venkatesh K, Chivatakarn O, Lee H, Joshi PS, Kantor DB, Newman BA, Mage R, Rader C, Giger RJ (2005) The Nogo-66 receptor homolog NgR2 is a sialic acid-dependent receptor selective for myelin-associated glycoprotein. J Neurosci 25:808-822.

Wang JT, Kunzevitzky NJ, Dugas JC, Cameron M, Barres BA, Goldberg JL (2007) Disease gene candidates revealed by expression profiling of retinal ganglion cell development. J Neurosci 27:8593-8603.

Wang KC, Kim JA, Sivasankaran R, Segal R, He Z (2002) P75 interacts with the Nogo receptor as a co-receptor for Nogo, MAG and OMgp. Nature 420:74-78.

Wanner IB, Deik A, Torres M, Rosendahl A, Neary JT, Lemmon VP, Bixby JL (2008) A new in vitro model of the glial scar inhibits axon growth. Glia 56:1691-1709.

Williams D, Jung DW, Khersonsky SM, Heidary N, Chang YT, Orlow SJ (2004) Identification of compounds that bind mitochondrial F1F0 ATPase by screening a triazine library for correction of albinism. Chem Biol 11:1251-1259.

Williams G, Wood A, Williams EJ, Gao Y, Mercado ML, Katz A, JosephMcCarthy D, Bates B, Ling HP, Aulabaugh A, Zaccardi J, Xie Y, Pangalos MN, Walsh FS, Doherty P (2008) Ganglioside inhibition of neurite outgrowth requires Nogo receptor function: identification of interaction sites and development of novel antagonists. J Biol Chem 283:16641-16652.

Witte H, Neukirchen D, Bradke F (2008) Microtubule stabilization specifies initial neuronal polarization. J Cell Biol 180:619-632.

Yiu G, He Z (2003) Signaling mechanisms of the myelin inhibitors of axon regeneration. Curr Opin Neurobiol 13:545-551.

Zhou FQ, Snider WD (2005) Cell biology. GSK-3beta and microtubule assembly in axons. Science 308:211-214.

Zhou FQ, Walzer M, Wu YH, Zhou J, Dedhar S, Snider WD (2006) Neurotrophins support regenerative axon assembly over CSPGs by an ECMintegrin-independent mechanism. J Cell Sci 119:2787-2796. 